$\frac{228}{11-21 \cdot 80}$

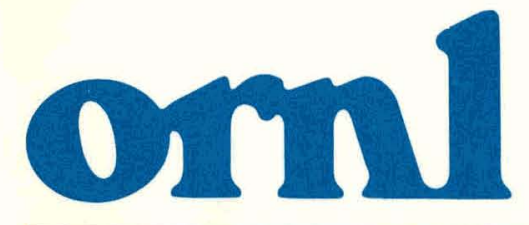

OAK RIDGE NATIONAL LABORATORY

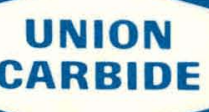

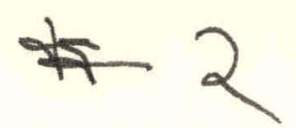

pr. 2036

ORNL/TM-7485

ENDF-297

\title{
User's Guide for SAMMY: A Computer Model for Multilevel R-Matrix Fits to Neutron Data Using Bayes' Equations
}

Nancy M. Larson

Francis G. Perey

OPERATED BY

UNION CARBIDE CORPORATION FOR THE UNITED STATES DEPARTMENT OF ENERGY 


\section{DISCLAIMER}

This report was prepared as an account of work sponsored by an agency of the United States Government. Neither the United States Government nor any agency Thereof, nor any of their employees, makes any warranty, express or implied, or assumes any legal liability or responsibility for the accuracy, completeness, or usefulness of any information, apparatus, product, or process disclosed, or represents that its use would not infringe privately owned rights. Reference herein to any specific commercial product, process, or service by trade name, trademark, manufacturer, or otherwise does not necessarily constitute or imply its endorsement, recommendation, or favoring by the United States Government or any agency thereof. The views and opinions of authors expressed herein do not necessarily state or reflect those of the United States Government or any agency thereof. 


\section{DISCLAIMER}

Portions of this document may be illegible in electronic image products. Images are produced from the best available original document. 


\section{Printed in the United States of America. Available from National Technical Information Service U.S. Department of Commerce 5285 Port Royal Road, Springfield, Virginia 22161 NTIS price codes-Printed Copy: A05 Microfiche A01}

This report was prepared as an account of work sponsored by an agency of the United States Government. Neither the U nited States Government nor any agency thereof, nor any of their employees, makes any warranty, express or implied, or assumes any legal liability or responsibility for the accuracy, completeness, or usefulness of any information, apparatus, product, or process disclosed, or represents that its use would not infringe privately owned rights. Reference herein to any specific commercial product, process, or service by trade name, trademark, manufacturer, or otherwise, does not necessarily constitute or imply its endorsement, recommendation, or favoring by the United States Government or any agency thereof. The views and opinions of authors expressed herein do not necessarily state or reflect those of the United States Government or any agency thereof. 
ORNL /TM-7485

ENDF-297

Dist. Category: UC-79d, LMFBR--

Physics, Base

Technology

Contract No. W-7405-eng-26

Engineering Physics Division

and Physics Division

Date Published: November 1980

User's Guide for SAMMY: A Computer Model for Multilevel R-Matrix Fits to Neutron Data Using Bayes' Equations

Nancy M. Larson

Computer Sciences Division

Francis G. Perey

Engineering Physics Division

Sponsor: J. A. Harvey

Physics Division

OAK RIDGE NATIONAL LABORATORY

Oak Ridge, Tennessee 37830

operated by

UNION CARBIDE CORPORATION

for the

DEPARTMENT OF ENERGY

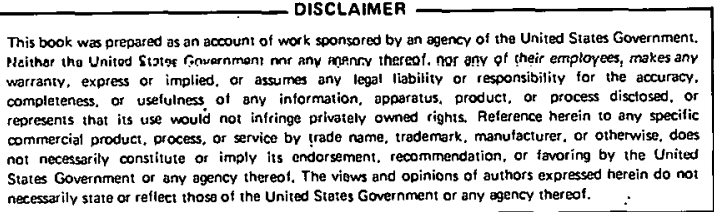
necessarily state or reflect thoso of the United States Government or any agency ther eol. 
THIS PAGE

\section{WAS INTENTIONALLY \\ LEFT BLANK}




\section{ACKNOWLEDGMENTS}

The authors wish to thank G. F. Auchampaugh for providing us with his least-squares multilevel R-matrix code MULTI, from which we borrowed extensively in preparing SAMMY. We acknowledge the assistance of P. W. Gaffney regarding numerical aspects of solving Bayes' equations. Thanks go also to F. H. Froehner and G. deSaussure for carefully reviewing this paper in manuscript form. Finally, we wish to thank Sherry Tilley, Betty Waddell, and Jan Lundy for typing the manuscript.

This research was supported by the Division of Nuclear Sciences, U. S. Department of Energy, Contract No. W-7405-eng-26, with Union Carbide Corporation. 
THIS PAGE

\section{WAS INTENTIONALLY LEFT BLANK}


ABSTRACT

In this report we describe a method for determining the parameters of a model from experimental data based upon the utilization of Bayes' theorem. This method has several advantages over the least-squares method as it is commonly used; one important advantage is that the assumptions under which the parameter values have been determined are more clearly evident than in many results based upon least squares. Bayes' method has been used to develop a computer code which can be utilized to analyze neutron cross-section data by means of the R-matrix theory. The required formulae from the $R$-matrix theory are presented, and the computer implementation of both Bayes' equations and R-matrix theory is described. Results of our analysis of $\mathrm{Ni}^{60}$ transmission data from ORELA and of several artificial data sets, and a comparison of our results with those of an earlier multilevel R-matrix code, are also presented. Finally, details about the computer code and complete input/output information are given. 
THIS PAGE

\section{WAS INTENTIONALLY \\ LEFT BLANK}


TABLE OF CONTENTS

CHAPTER

PAGE

I. INTRODUCTION .................... 1

II. BAYES' THEOREM .................... 3

III. IMPLEMENTATION OF BAYES' EQUATIONS . . . . . . . 17

1. Solving the Equations ........... . 17

2. Adjusting for Approximations ......... 18

3. Introduction of Off-Diagonal Data Covariances . . 18

IV. MULTILEVEL R-MATRIX THEORY . . . . . . . . . . 21

V. IMPLEMENTATION OF MULTILEVEL R-MATRIX THEORY . . . . . 25

VI. CALCULATIONS AND COMPARISONS . . . . . . . . . 31

1. $\mathrm{Ni}^{60}$ Transmission Data ............. . 31

2. The Effect of Improperly Fitted S-Wave on Neighboring P-Wave Resonance ... . . . . 38

3. Errors in Background Subtraction... . . . . . 42

4. Simultaneous vs. Sequential Analysis of S-Wave ... 43

VII. SUMMARY AND CONCLUSIONS ............ . . 49

REFERENCES ........................ . . 51

APPENDIX A. ALGEBRAIC DETAILS . . . . . . . . . 53

1. Deriving Bayes' Equations .. . . . . . . 53

2. Iteration Scheme ........... . . 57

3. Derivation of Least Squares from Bayes' Equations . 58

4. Use of Data Covariances to Indicate Coherent Data Corrections ................ 60

5. Derivative of $x^{-1}$ with Respect to $\mathrm{R}$....... 61

APPENDIX B. DESCRIPTION OF THE COMPUTER CODE SAMMY . . . . . 63

1. Dynamic Allocation of Array Storage ....... 63

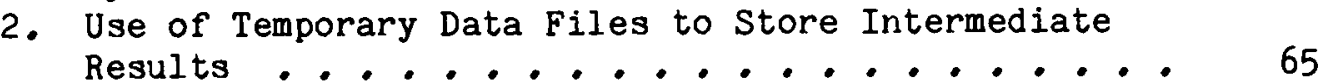

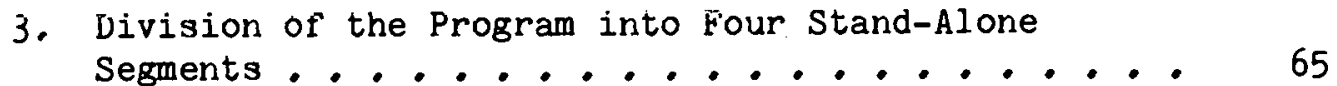

4. Conversion to other Computer Systems ....... 72

APPENDIX C. INPUT TO SAMMY ............. . . 73

APPENDIX D. SAMPLE INPUT AND OUTPUT . . . . . . . . 89

APPENDIX E. FORTRAN LISTINGS . . . . . . . . . . . . 91 


\section{THIS PAGE WAS INTENTIONALLY \\ LEFT BLANK}




\section{LIST OF TABLES}

TABLE

PAGE

IV.1. PENETRATION FACTORS P, LEVEL SHIFT FACTORS S, AND POTENTIAL-SCATTERING PHASE SHIFTS $\phi$ FOR ORBITAL ANGULAR MOMENTUM $\ell$, CENTER OF MASS MOMENTUM $k$, AND CHANNEL RADIUS $a_{c}$; WITH $\rho=k a_{c} . . . . . . . . . . . . .22$

VI.1. COMPARISON OF MULTI AND SAMMY RESULTS FOR NI 60 TRANSMISSION DATA . . . . . . . . . . . 33

VI.2. PARAMETER VALUES FOR EXAMPLE NUMBER 2, DECOUPLING P-WAVE RESONANCE FROM AN IMPROPERLY FITTED S-WAVE BACKGROUND . • • 39

VI.3. PARAMETER VALUES FOR EXAMPLE NUMBER 3 USING CONSTANT DATA COVARIANCE TO OFFSET IMPROPER BACKGROUND SUBTRACTION . . . 44

VI.4. SIMULTANEOUS VS. SEQUENTIAL ANALYSIS OF AN S-WAVE RESONANCE FOR TWO SETS OF STARTING VALUES . . . . . . . 47

B.1. ILLUSTRATION OF DYNAMIC ALLOCATION OF ARRAY STORAGE.. .64

B.2. TEMPORARY FILES USED BY SAMMY ............. 66

B.3. SEgMenTS OF THE COdE SAMMY .............. 67

C.1. FORMAT OF THE INPUT FILE ............... 74

C.2. ACCEPTABLE "ALPHANUMERIC INFORMATION CONCERNING PROGRAM OPTIONS" FOR CARDS $3,4, \ldots$ IN THE INPUT FILE . . . . . . 77

C.3. FORMAT of THE PARAMETER FILE . . . . . . . . . . 78

C.4. FORMAT OF THE DATA FILE .............. 80

C.5. FORMAT OF THE DCV FILE ................ 81

C.6. TELETYPE INPUT FOR SAMMY ............... 83

C.7. SAMMY OUTPUT FILES ................ 84

C.8. TELETYPE INPUT FOR SAMSWI . . . . . . . . . . 85

C.9. TELETYPE INPUT FOR SAMøDF .............. 86

C.10. SECTIONS OF ØDF FILÈ GENERATED BY SAMøDF . . . . . . . 87 
THIS PAGE

\section{WAS INTENTIONALLY \\ LEFT BLANK}




\section{LIST OF FIGURES}

FIGURE

VI.1. Theoretical curves resulting from MULTI and SAMMY analyses of $\mathrm{Ni}^{60}$ data ( $\mathrm{HA80}$ ), corresponding to the five parameter sets listed in Table VI.1............ 36

VI.2. Artificial data used to study the effect of an improperly fitted s-wave on a neighboring p-wave resonance...... 41

VI.3. Artificial data used to study the effect of improperly subtracted background.............. . 45

B.1. Tree charts showing the subroutine structure of segment SAMMY-PARAMETER . . . . . . . . . . . 68

B.2. Tree charts showing the subroutine structure of segment SAMMY-DATA. ................... 69

B.3. Tree charts showing the subroutine structure of segment SAMMY-THEØRY. .............. 70

B.4. Tree charts showing the subroutine structure of segment SAMMY-RESULTS. . . . . . . . . . . . . 71 


\section{INTRODUCTION}

The nonlinear least-squares method is frequently used for obtaining estimates of parameters of a model by fitting experimental data. This procedure requires an initial estimate of the parameters of the model which are modified in an iterative fashion to minimize the value of $x^{2}$. The method also provides an estimate of the errors in the parameters. Although the method of least-squares is widely used and has a wellunderstood theoretical foundation, in practice it is not totally free from problems. As the method is usually implemented and used, three difficulties often arise: i) the extent to which the final parameters are dependent upon the starting values is not known and is hard to assess; ii) when all parameters of the model are allowed to be adjusted, some of them frequently end up with values which are perceived to be unphysical; and $i i i)$ the estimate of the errors which the method provides are often perceived to be unreasonably small. How serious are these problems of course varies from case to case. The usefulness of the results obtained depends to some degree upon how serious these problems are in any given situation and what was done specifically to alleviate them. Corisequently, this procedure which was expected to yield objective and well-understood answers, provides results which must be evaluated with great care. This is particularly true when we are interested in combining the information obtained from different experiments and the problems of fitting the data were not handled in a consistent fashion in the different experiments. 
In Section II of this report we describe a method for determining the parameters of a model from experimental data based upon the utilization of Bayes' theorem. This method has several advantages over the least-squares method as it is commonly used; one important advantage is that the assumptions under which the parameter values have been determined are more clearly evident than in many results based upon least squares. The method has been used to develop a computer code (SAMMY) which can be utilized to analyze neutron cross-section data by means of the $\bar{R}$-matrix theory. The required formulae from the R-matrix theory are presented in Section IV. Sections III and V describe the computer implementation of Bayes' equations and R-matrix theory, respectively. Results of our analysis of $\mathrm{Ni}^{60}$ transmission data from ORELA and of several artificial data sets, and a comparison of our results with those of an earlier multilevel R-matrix code, are given in Section VI. A brief summary appears in Section VII.

Five appendices complete this report: Miscellaneous algebraic details, too involved to be presented in the text, are given in Appendix A A description of the computer code, including a detailed discussion of its space-saving features, is given in Appendix B. Appendix C explains input to and output from SAMMY, and input and output for a simple example are given in Appendix D. Finally, the code itself is listed in Appendix E. 


\section{BAYES' THEOREM}

In this section we derive the formulae used in the code SAMMY to obtain the values of the parameters and their uncertainties using Bayes' theorem. We emphasize the conditions under which the formulae are applicable and the relationship of our results to the customary leastsquares method. We adopt in this section the usual mode of description based on the theory of statistics since the reader is familiar with it. Derivation of our results from a different point of view will be presented elsewhere (PE79, PE80a).

Bayes' theorem is usually written:

$$
p(A \mid B) \propto p(A) p(B \mid A)
$$

where:

A represents the parameters of the model and $B$ the data. $p(A \mid B)$ is the probability for the value of the parameters conditional upon the data $B$, and is what we seek. It is conventional to call $p(A \mid B)$ the posterior probability. When A represents several parameters, $p(A \mid B)$ is a joint probability density function (joint pdf). The expectation values of $p(A \mid B)$ are taken as the estimates for the parameters and its covariance matrix gives us a measure of how well the parameters are determined and of the parameters' interdependencies.

$p(B \mid A)$ is the probability for observing the data $B$ given the parameters A. It is a function of the parameters $A$ of the model and is known as the likelihond function of the data $B$.

$p(A)$ is the joint pdf for the value of the parameters $A$ of the model, prior to consideration of the data $B$. It is known as the prior joint pdf. The expectation values of $p(A)$ are the prior estimates for 
the values of the parameters and its covariance matrix gives a measure of how well the parameters are known before consideration of the data.

The constant of proportionality in Eq. (II.1) can be determined from the normalization condition.

The use of Eq. (II.1) as an estimator is considered controversial in many textbooks unless $\mathrm{p}(\mathrm{A})$ is an estimated joint pdf based upon some data or considered as an hypothesis. In order to avoid this problem, we will consider that the prior $p(A)$ is based upon some data which we will denote by $\mathrm{X}$, and rewrite $\mathrm{Eq} .(\mathrm{II}, 1)$ as:

$$
p(A \mid B X) \propto p(A \mid X) p(B \mid A X) .
$$

In this form Bayes' theorem is always acceptable and has the meaning that $\mathrm{p}(\mathrm{A} \mid \mathrm{BX})$ is the joint pdf based upon both data $\mathrm{X}$ and data $\mathrm{B}$. It is often said that Eq. (II.2) is an "adjustment equation" where the estimates of the values of the parameters, from $p(A \mid X)$, are adjusted on the basis of the data B to provide a new set of estimates. It should be noted at this stage that the form of Eq. (II.2) is valid only if the data $B$ and $X$ are independent. The extent to which the value of the parameters and their uncertainties are changed as a result of using $\mathrm{Eq}$. (II.2) is a function of how accurate are the data $B$ and how sensitive they are to the parameters. We postpone until later a discussion of the data $X$.

Let $A=\left\{P_{k}\right\}$ for $K=1$ to $K$ be the set of all parameters of the multilevel R-matrix theory. We use instead of $A$ the letter $P$ without an index to represent the $\mathrm{K}$-dimensional column vector whose components are the $\mathrm{P}_{k}{ }^{\prime} \mathrm{s}, \mathrm{i} . \mathrm{e}$. ,

$$
P=\left\{P_{k}\right\}, \quad k=1,2, \ldots, K
$$


We assume that the joint $\operatorname{pd} f(A \mid X)$ is a joint normal pdf having as an expectation value the vector $\bar{P}$ and a covariance matrix $M$. Under this assumption we have:

$$
p(A \mid X) \propto \exp \left[-1 / 2(P-\bar{P})^{t} M^{-1}(P-\bar{P})\right],
$$

where. $P$ is the "true" value of the parameters and the superscript $t$ denotes the transpose.

The experimental data which we had symbolized by $B$ and which is to be described by the R-matrix theory will now be represented by a data vector $D$ whose components $D^{i}$ are the $L$ data points. We also assume that the experimental conditions are such that the data $D, i . e$. the $D^{i}$ 's, have a joint normal distribution about their "true" value $\mathrm{T}$ and the covariance matrix will be denoted by $V$. We therefore have the likelihood function,

$$
p(B \mid A X) \propto \exp \left[-1 / 2(D-T)^{t} V^{-1}(D-T) \cdot\right]
$$

If, as we have just stated, $T$ stands for the true value of the data, then the covariance matrix $V$ represents the experimental "errors" of the data. The diagonal elements of $\mathrm{V}$ are the variances of the data points; and the off-diagonal elements, i.e. the covariances $v^{i j}$, represent the errors which jointly affect the data points $D^{i}$ and $D^{j}$. It is conventional to state that the of $f$-diagonal elements represent the correlated errors in the data. Although data are usually reduced in such a fashion that important correlations between data points are introduced, existing data analysis codes usually have no provisions for a nondiagonal covariance matrix V (PE $80 \mathrm{~b})$. This is a major deficiency, which our code remedies. (Note that the inclusion of off-diagonal data covariances is not restricted to Bayes' method but could be done with 
least-squares as well.) The importance of including correlations is illustrated by the examples in Section VI of the report.

We now need to relate the "true" value of the data $T$ to the parameters $P$. Ideally $T$ can be calculated exactly from the model, in our case the R-matrix theory. In practice it is not always so since the observed quantity often cannot be reduced to the form of cross sections because of various "experimental" problems such as Doppler broadening, multiple scattering, experimeñál resolutiori, etc. What is often done is to calculate the cross sections on the basis of the theory and then "fold Into them" various effects to produce an estimate of the "true" values of the data $D$. In this process various approximations are used. In the likelihood function, Eq. (II.5), V must therefore be modified to include an estimate of the uncertainties in the theoretically calculated values $T$. These uncertainties are very often correlated over the range of the data being analyzed and contribute to the fact that the covariance matrix $V$ is nondiagonal. In most data analysis codes used today, this problem is totally ignored and cannot be handled adequately since $V$ is restricted to be diagonal. In what follows we will consider $v$ to include all of the uncertainties: those from the data $D$ and those from the theoretical estimates $\mathrm{T}$ based upon the R-matrix theory.

In the likelihood function; Eq. (II.5), we need to calculate $T$ as a function of $r$, the true value of the parameters. This is done formally by considering $\mathrm{T}$ a function of $\mathrm{P}$ and performing a Taylor expansion about $\overline{\mathrm{P}}$, the expectation value of $\mathrm{p}(\mathrm{A} \mid \mathrm{X})$, and keeping only the Iinear terms:

$$
T(P) \simeq \bar{T}+G(P-\bar{P})
$$

where $\overline{\mathrm{T}}$ is equal to $\mathrm{T}(\overline{\mathrm{P}})$. 
Since $T$ is a vector of dimension $L$ (equal to the number of data points), and $P$ is a vector of dimension $K$ (equal to the number of parameters), the sensitivity matrix $G$ is of dimension $L \times K$. The elements of $G$ are the partial derivatives of $T^{n}$ with respect to the parameters $P_{k}$ evaluated at $P=\bar{P}$ :

$$
G_{k}{ }^{n}=\left.\frac{\partial T^{n}}{\partial P_{k}}\right|_{P=\bar{P}}
$$
and $\mathrm{k}=1,2, \ldots, \mathrm{K}$

Substituting Eq. (II.6) into Eq. (II.5) and using Eq. (II.4) we obtain for the posterior joint pdf (Eq. (II.2)):

$$
\begin{aligned}
p(A \mid B X) \propto \exp \left[-1 / 2\left\{(P-\bar{P})^{t} M^{-1}(P-\bar{P})+\right.\right. & \\
& \left.\left.(D-\bar{T}-G(P-\bar{P}))^{t} \cdot V^{-1}(D-T-G(P-\bar{P}))\right\}\right] .
\end{aligned}
$$

Because of the three basic assumptions we have made, i.e.,

i) the prior joint pdf is a joint normal,

ii) the likelihood function is a joint normal, and

iii) the true value is a linear function of the parameters, the posterior joint pdf is also a joint normal. Denoting its expectation value by $\bar{P}^{\prime}$ and its covariance matrix by $M^{\prime}$, we may write:

$$
\mathrm{p}(\mathrm{A} \mid \mathrm{BX}) \propto \exp \left[-1 / 2\left(\mathrm{P}-\overline{\mathrm{P}}^{\prime}\right)^{t} M^{\mathbf{P}^{-1}}\left(\mathrm{P}-\overline{\mathrm{P}}^{\prime}\right)\right] .
$$


As shown in Apperdix A, equating the linear and quadratic terms of the exponents in Eqs. (II.8) and (II.9) yields our final results, hereafter referred to as Bayes' equations:

$$
\begin{aligned}
& \bar{P}^{\prime}-\bar{P}=M G^{t}(N+V)^{-1}(D-T), \\
& M-M^{\prime}=M G^{t}(N+V)^{-1} G M^{t},
\end{aligned}
$$

where the $L \times L$ matrix $N$ is defined as

$$
N=G M G^{t} \text {. }
$$

The matrix $\mathrm{N}$ is the covariance matrix of the joint pdf for the true value of the data based upon our prior pdf for the value of the parameters. As is clear from Eq. (II.8) and therefore reflected in Bayes' equations, the prior data $X$ and the data $B$ are treated on an equal footing. From Eq. (II.11) we see that it is the relative size of the elements of the matrix $\mathrm{N}$ and $\mathrm{V}$ which determines the extent to which the uncertainties in the parameters are changed. In the limit where the matrix $M$ is diagonal and its elements tend to infinity, Bayes' equations become the familiar least-squares equations. Algebraic details are oiven in Appendix A.

The results, Eq. (II, 10) and $E q$. (II, 11), are valid only if the three assumptions under which they were derived from Bayes' theorem are valid. In practice we use these equations when the assumptions are only approximately true; in the remainder of this section we discuss the consequences of this and the relationship of the results to the usual method of least-squares. 
Instead of starting from Bayes' theorem we could have obtained our results (II.10) and (II.11) by postulating that we should minimize $X^{2}$, given by:

$$
X^{2}=(P-\bar{P})^{t} M^{-1}(P-\bar{P})+(D-T)^{t} V^{-1}(D-T) . \quad(I I .13)
$$

Data analysis codes which use the conventional least-squares method take as a starting point the fact that they want to minimize the second term of (II.13) to produce the result which we will call $\hat{P}$ and $\hat{M}$. The practical difficulties in that approach come from the non] inearity of $T$ with respect to the parameters $P$. The advantages and disadvantages of the method we are proposing derive solely from the inclusion of the first term in Eq. (II.13). It is clear from Eq. (II.13) that, if $M$ is diagonal and its elements become very large, we recover the conventional leastsquares results as already meritioned.

Bayes' equations were derived on the assumption that we could approximate $T(P)$ by the first two terms of the Taylor expansior about $\bar{P}$. In the usual. least-squares method this same linear approximation is made, but about $\hat{P}$ which minimizes the second term of Eq. (II.13). The value of $\hat{P}$ must be obtained by an iteration method; difficulties, when they occur, stem from the fact that the $x^{2}$ surface does not exhibit a well-defined minima for some of the parameters $\mathrm{P}_{k}$. This tends to occur for two classes of parameters $P_{k}$. The first class consists of those parameters for which the data $D$ have very little sensitivity and the minimum is therefore very broad. The linearity approximation is not at fault here; rather, the parameters are not well determined by the data, and the "noise" in the data causes the maximum of the likelihood function to be far from what is perceived to be a physically reasonable 
value. This often occurs because of some approximation in the theoretical calculation. The other class for which difficulties occur with the converitional least-squares method are those parameters for which the $x^{2}$ surface exhibits a "valley" in parameter space which extends beyond the domain of physically reasonable values, even though the partial derivatives of the theory with respect to these parameters may be large. For both classes of parameters for which the conventional leastsquares method has difficulties, the linear expansion of $T(P)$ about $\bar{P}$ may not be a very good one and Bayes' method may also have difficulties. However, it is possible to improve upon formulae (II.10) and (IT.11) hy iterating in order to use an expansion of $T(P)$ about $\bar{P}^{\prime}$ instead of $\bar{P}$. The way in which this can be done is to estimate $\overline{\mathrm{P}}^{\prime}$ by first doing the expansion about $\overline{\mathrm{P}}$; let us call this result ${ }^{\circ} \overline{\mathrm{P}}^{\prime}$. Then, in Eq. (II.10) and (II.11) instead of calculating $T$ and $G$ at $P=\bar{P}$, we calculate them at $P=$ ${ }^{\circ} \mathrm{P}$ ' and obtain a new estimate ${ }^{\prime} \bar{P} \cdot$. In principle one can iterate in this fashion until convergence is obtained. In practice it is seldnm nenes= sary to do so more than once since further iteration merely improves the precision of the $\mathrm{F}_{k}^{\prime}$ s beyond a limit justified by the accuracy with which they are determined. The presence of $\bar{P}$ and $M$ in Eq. (II.10) and (II.11), unless the values of the diagonal elements of $M$ are very large, prevents the solution from "running away" as it often does in the conventional least-squares method. We emphasize that in iterating Bayes' equations the values of $\bar{P}$ and $M$ are left at their input values and it is only the quantities denoted by $\bar{T}$ and $G$ which are recalculated at the previously estimated value of $\bar{p}^{\prime}$. Algebraic details are given in Appendix A. 
The "solution" to the problems we often encounter with the conventional method of least squares has been bought at the price that we must provide $\bar{P}$ and $M$. Even if the matrix $V$ were diagonal, the matrix $N$ will be nondiagona]. and it is the matrix $\mathrm{N}+\mathrm{V}$ which must be inverted. Therefore we no longer have any. incentive to approximate $\mathrm{V}$ by a diagonal covariance matrix. The consequence of introducing $\bar{P}$ and $M$ when they are known is that $\bar{P}^{\prime}$ and $M^{\prime}$ are not independent of $\bar{P}$ and $M$. As we have. emphasized in discussing Bayes' theorem, $\bar{P}$. and $M$ must be based upor some data or be treated as an hypothesis, in which case we say that $\bar{P}$ ' and. $M$ ' are conditional upon the validity of our hypothesis.

We will first discuss the case where $\bar{P}$ ard $M$ are obtained from an analysis of some actual data $X$. (As pointed out earlier the data. D must be independent of $X$; it is possible to modify Eq. (II.13) when the data $D$ are not independent of $\bar{P}$ but we shall not consider this case here.) That is, the analysis of data $X$ yielded an approximately normal joint pdf for the true value of $P$, at least in the neighborhood of $\bar{P}$; the central limit theorem ensures that this approximation is usually valid. Then the results $\bar{P}$ ' and $\dot{M}^{\prime}$ which we obtain using Bayes' equat.ions will be identical to those obtained in the usual procedure where we first obtain $\hat{P}$ and $\hat{M}$ and then "combine" this value with $\bar{P}$ and $M$ in the least-squares sense. If the model is nonlinear, the results of the two procedures will differ slightly since in one case the linear expansion is made about $\bar{P}$, and in the other about $\hat{P}$.

Formula (II.13), although to our knowledge not used in current differential nuclear data analysị, is used in many codes to perform "data adjustment" where $\bar{P}$ and $M$ are the "differential data". and $D$ are some , . 
"integral data". Ir our approach we take $P$ to be the parameters of the theory and $\mathrm{D}$ to be the differential data. There is a practical problem with simultareously evaluating and analyzing data as our formulae does: if two different sets of data ${ }^{1} D$ and ${ }^{2} D$ are analyzed separately but using the same values of $\bar{P}$ and $M$ derived from data $X$, then it is a practical. impossibility to combine the output of the two analyses, say $\bar{P}^{\prime}$, and ${ }^{2} \bar{P}^{\prime}$, because they are correlated in some unknown fashion. This problem is of course to be contrasted with the one faced in the conventional. least-squares approach, where we also cannot combine the analyses of data ${ }^{1} D$ and ${ }^{2} D$ if some of the physical parameters are fixed at different values or if different sets of the parameters are adjusted. We now consider the situation when $\bar{P}$ arid $M$ do not come in their entirety from the analysis of some specific data $X$ but may be considered an hypothesis. The resul.ts $\bar{P}^{\prime}$ and $M^{\prime}$ of the analyses of data $D$ are furctions of $\bar{P}$ and $M$, and in the future will be of interest to us orily if we are willing to continue to entertain this same hypothesis. We may in fact view the usual least-squares procedure (where some of the parameters are fixed at specific values and $\chi^{2}$ is minimized by varying some other parameters) as producing an analysis of the data $D$ which is valid conditional upon the hypothesis that all the fixed parameters have a true value equal. to the value at which they were fixed. This may well. be a very good hypothesis to consider at the time the data is analyzed or to answer some specific questions, but the utility of the results ceases the moment the hypothesis is no longer justified. Our method based upon Bayes' theorem can be viewed as equivalent to what is usually done, if $M$ is taken as diagonal, the $M_{k k}$ corresponding 
to fixed parameters are set infinitely small, and the $M_{k k}$ corresponding to the adjusted parameters are set infinitely large. If we adopt this point of view, our procedure, where all of the elements $M_{i j}$ are finite, becomes just a constrained leașt-squares method. Its great advantage is that it allows us to reduce the data $D$ using a far less drastic hypothesis than we are often forced to use, and the results will more Jikely be considered useful much longer. Often data does exhibit very small sensitivity to some parameters, and large sensitivity to some other parameters, but there are many intermediate cases. Our method can be viewed as a way to obtain the joirt pdf for the true value of the parameters $P_{k}$ based upon the $\chi^{2}$ surface in a specified region of parameter space defined by $\bar{P}$ and $M$. It can be argued that this method does not solve the problems we often encounter with the method of leastsquares as much as it provides a way to cope with them in a more generally useful way. It is therefore very important when reporting the results $\overline{P^{\prime}}$ and $M^{\prime}$ that we specify clearly the values of $\bar{P}$ and $M$ upon which they are based. The extent to which $\bar{P}^{\prime}$ differs from $\bar{P}$, but more importantly how the matrix elements of $M^{\prime}$ differ from those of $M$, tells us what we have learned about the parameters from the data $D$. The results $\bar{P}^{\prime}$ and $M^{\prime}$ will continue to be useful as long as we consider $\bar{P}$ and $M$ a reasonable hypothesis.

Finally the method ::e propose should provide a more realistic assessment of the uncertainties in the parameters. There are three major reasons why urrealistically small values for the uncertainties in the parameters are usually obtained in the conventional procedure. Two of the reasons are not related to our introduction of $\bar{P}$ and $M$ in the 
procedure but are related to the fact that the covariance matrix $\mathrm{V}$ is usually taken as diagonal. In most instances the data $D$ to be analyzed results from manipulations and corrections made to experimentally observed quantities. Because these corrections and transformations in the data are not exact, properly propagated "errors" would yield a nondiagonal matrix $V$. The magnitudes of the elements of the matrix $M$ ' are very sensitive functions of the elements of $v$ and are strongly affected by the nondiagonal elements of $\mathrm{V}$. Secondly, in our calculations of the theoretical values of the data, which we have called $\mathrm{T}$, we also make approximations; the matrix $\mathrm{V}$ should contain a contribution due to the uncertainties arising from these approximations. (The matrix $\mathbb{N}$ does not represent the uncertainties due to the approximations in the theoretical calculations.) The contributions to $\mathrm{V}$ due to the approximations in the theoretical calculation $\mathrm{T}$ are also highly nondiagonal. Until the effort is made to use realistic covariance matrices for $\mathrm{V}$, the results of our analyses will not be reliable and in particular our estimates of the uncertainties in the parameters will not be reliable. Since the code described in this report does allow for a nondiagonal covariance matrix $\mathrm{V}$ and since no computer time is saved when $\mathrm{V}$ is diagonal, we urge users of the code to input more realistic covariance matrices for $V$. The burden of providing the "theoretical component" of. the matrix $V$ should normally be part of the code but has not yet been implemented in an automatic fashion in the code SAMMY. However, some options have been provided for generating some off-diagonal elements; these options should be used when appropriate to relieve the burden of preparing the input data. 
The final reason why we often get too small uncertainties in the parameters is that, when we fix some parameters, the diagonal elements of the matrix $M^{\prime}$ are wrongly identified as the variance of the marginal pdf's of the parameters being varied. This, however, is true only if the joint pdf of ald the parameters has a diagonal covariance matrix. Through the introduction of $\bar{P}$ and $M$ we allow for the possibility of obtaining the full joint pdf of all the parameters. The diagonal elements of this full joint pdf are also the variances of the marginal pdf's of the parameters and do provide a realistic measure of how well we know each individual parameter. It is very important to report the full covariance matrix $M^{\prime}$ since it is essential for most applications to know the off-diagonal elements of $M^{\prime}$. We recognize that this is a new burden on the user but we believe that, if a realistic covariance matrix $V$ is used, the full covariance matrix $M^{\prime}$ is meaningfully produced by the code. 


\section{THIS PAGE}

\section{WAS INTENTIONALLY \\ LEFT BLANK}


III. IMPLEMENTATION OF BAYES' EQUATIONS

1. Solving the Equations

Implementation of Bayes' equations is straightforward. In matrix form, these equations can be written

and

$$
\overline{\mathrm{P}}^{\prime}=\overline{\mathrm{P}}+\mathrm{MG}^{\mathrm{t}}(\mathrm{N}+\mathrm{V})^{-1}(\mathrm{D}-\overline{\mathrm{T}}),
$$

and

$$
M^{\prime}=M-M G^{t}(N+V)^{-1} G M \text {, }
$$

where

$$
N=G M G^{t} \text {. }
$$

Solving Eqs. (III.1) and (III.2) is equivalent to solving

$$
A X=Y
$$

$K+1$ times (where $K$ is the number of parameters for the problem), with A the $L \times L$ symmetric matrix $N+V$ (where $L$ is the number of data points), and $Y$ a column matrix equal to $(D-\bar{T})$ in Equation (III.1) or equal to each of the $K$ columns of the rectangular matrix GM in Equation (III.2).

Prudent numerical analysis procedure dictates that the inverse of a matrix never be evaluated directly. Rather, the matrix A is first factorized as

$$
A=U B U^{t}
$$

where $B$ is a block-diagonal matrix, and $U$ is the product of elementary unit triangular and permutation matrices, so that inverses of $U$ and $B$ are immediately avajlable. The solution $X$ is then found from

$$
X=\left(U^{-1}\right)^{t} B^{-1} U^{-1} Y
$$


In SAMMY, the factorization (III.5) is performed by LINPACK (D079) subroutine SSPCØ, and the $(K+1)$ solutions are obtained by LINPACK subroutine SSPSL. Subroutine NEWPAR oversees these operations. Further details are given in the report on program BAYES (LA80).

\section{Adjusting for Approximations}

It is necessary to modify this procedure slightly to account for the approximations built into Bayes' equations. As explained in Appendix A, an iteration scheme has been derived to correct for the nonlinear relationship between parameters and theoretical values. In SAMMY, a single iteration is performed, since (1) further iteration is expected to increase precision but not accuracy, and (2) test cases have shown this to yield consistent results. (See, e.g., example 4 of Section VI).

\section{Introduction of Off-Diagonal Data Covariances}

Often $\ell>0$ resonance parameters cannot be determined accurately because the underlying $\ell=0$ structure is not well known. Introduction of a constant on- and off-diagonal data covariance in the neighborhood of the non-s-wave resonance permits effective decoupling of the s-wave from the non-s waves. This occurs because an additive constant covariance is mathematically equivalent to a constant, coherent correction term for either the data or the theory; algebraic details are presented in Appendix A. Th1s type of off-diagonal data covariance matrix can be generated automatically by SAMMY, if the user so desires.

One other type of off-diagonal data covariance matrix which can be automatically generated by SAMMY is of the form

$$
v^{i j}=\nabla^{i j}+\left(a+b E^{i}\right)\left(a+b E^{j}\right)
$$


where $\bar{V}^{i j}$ is supplied by the user, $E^{i}$ is the energy for data point $i$, and a and $b$ are constants chosen by the user. This type of covariance is useful if there are energy-dependent coherent uncertainties in the data, for example, if a subtracted background is imperfectly known.

Other types of off-diagonal data covariances may be supplied directly by the user. Details for inputting all types of covariances are provided in Appendix C. Examples using off-diagonal data covariances are presented in Section VI. 
THIS PAGE

\section{WAS INTENTIONALLY \\ LEFT BLANK}


IV. MULTILEVEL R-MATRIX THEORY

Consider a neutron of energy $E$ incident on a target of spin $I$. The combined system (neutron plus target) has resonances $\lambda$ with spin and parity $\mathrm{J}^{\pi}$ at energies $\mathrm{E}$. These resonances may decay through any of several channels $c$ with spin s and orbital angular momentum $l$; the partial width for decay via channel $c$ is $\Gamma_{\lambda c}$. In addition, gamma decay is allowed, with partial width $\Gamma_{\lambda}^{\gamma}$.

Cross-sections for the interaction described above may be calculated from multilevel R-matrix theory (LA58) in the Reich-Moore approximation (RE58). An excellent review of R-matrix theory and its relationship to other resonance formalisms is presented in the recent article by Froehner (FR80); the reader interested in both derivation and details is referred to that article. Here we present only the relevant formulae, beginning with the R-matrix itself:

$$
\mathrm{R}_{\mathrm{cc}^{\prime}}^{\mathrm{J}^{\pi}}=\sum_{\lambda} \frac{\gamma_{\lambda c^{\prime}} \gamma_{\lambda c^{\prime}}}{E_{\lambda}-E-i \alpha_{\lambda}^{2}},
$$

where all levels (resonances) with total spin and parity $J^{\pi}$ are included in the sum. The channel width $\Gamma_{\lambda c}$ is given in terms of the reduced width $Y_{\lambda c}$ by

$$
\Gamma_{\lambda c}=2 \gamma_{\lambda c}^{2} P_{\ell}
$$

where $\mathrm{P}_{\ell}$ is the penetration factor, which depends only on the orbital angular momentum $\ell$ and the energy $\mathrm{E}$; formulae for $\mathrm{P}_{\ell}(\mathrm{E})$ are shown in l'able IV.1. Similarly, the gamma width $\Gamma_{\lambda}^{\gamma}$ is given in terms of the reduced 
T'ABLE IV.1. PEVE.RATION FACTORS F, LEVEL SHIFT FACTORS $S$, AND PCTENTIAL-SCATTERING YHASE SHIF'S FOR GRBITAL AVGDIAR MONENTUM 2 , CENTER OP MASS MOMENTUM $k$, AND CHANNEL RADIUS $a_{0}$, WITH $\rho=k$ a

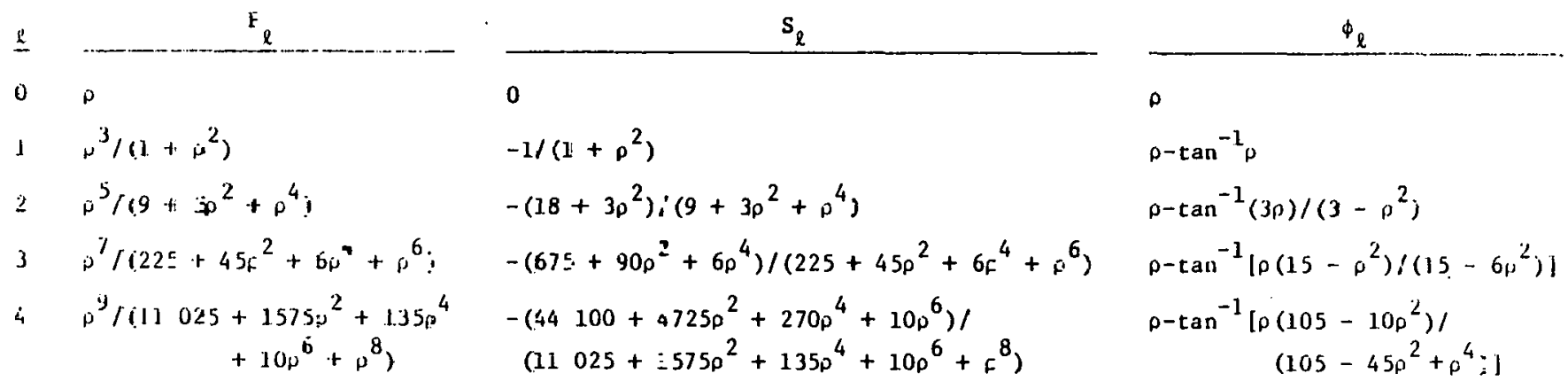


gamma width $\alpha_{\lambda}$ as

$$
\Gamma_{\lambda}^{\gamma}=2 \alpha_{\lambda}^{2}
$$

The R-matrix is related to physical observables via the $W$-matrix which, in matrix notation, is given by

$$
W=P^{1 / 2}(I-R L)^{-1}\left(I-R L^{*}\right) P^{-1 / 2} \quad .
$$

SAMMY uses a different but equivalent form for $W$ :

$$
W=I-\frac{2 i P}{L}+2 i \frac{\sqrt{P}}{L}\left(\frac{1}{L}-R\right)^{-1} \frac{\sqrt{P}}{L} .
$$

The quantity $\mathrm{L}_{\ell}$ in $\mathrm{Eq} .(\mathrm{IV} .4)$ is given by

$$
L_{\ell}=\left(S_{\ell}-B_{\ell}\right)+i P_{\ell}
$$

with $S_{\ell}$ the shift factor, shown in Table IV.1, and $B_{\ell}$ the arbitrary boundary constant at the channel radius $a_{c}$. "I" in Eq. (IV.4) represents the identity matrix.

Integrated cross sections are then given in terms of $\mathrm{W}$ and the potential scattering phase shift $\phi$, also shown in l'able IV.1, as f'ollows:

$$
\begin{gathered}
\sigma^{\text {total }}=\frac{2 \pi}{\mathrm{k}^{2}} \sum_{\mathrm{J}} \mathrm{g}_{\mathrm{J}} \sum_{\begin{array}{c}
\text { incident } \\
\text { channels } \\
\mathrm{c}
\end{array}}\left(1-\operatorname{Re}\left(\mathrm{e}^{-2 \mathrm{i} \phi} \ell \mathrm{W}_{\mathrm{cc}}^{\mathrm{J}}\right)\right) \\
\left.\sigma^{\text {elast1c }}=\frac{\pi}{\mathrm{k}^{2}} \sum_{\mathrm{J}} \mathrm{g}_{\mathrm{J}} \sum_{\substack{\text { incident } \\
\text { channels } \\
\mathrm{c}}}\left(1-2 \operatorname{Re}\left(\mathrm{e}^{-2 \mathrm{i} \phi} \ell \mathrm{W}_{\mathrm{cc}}^{\mathrm{J}}\right)+\sum_{\substack{\text { incident } \\
\text { channels } \\
\mathrm{c}^{\prime}}}\left|\mathrm{W}_{\mathrm{cc}}^{\mathrm{J}}\right|^{2}\right)\right)_{(\mathrm{IV} .7)}
\end{gathered}
$$




$$
\sigma^{\text {reaction }}=\frac{\pi}{k^{2}} \sum_{J^{\prime}} g_{j} \sum_{\substack{\text { incident } \\ \text { channels } \\ c}} \sum_{\substack{\text { channels } \\ c^{\prime}}}\left|W_{c^{\prime} c^{\prime}}^{J^{\prime}}\right|^{2}
$$

$$
\sigma^{\text {capture }}=\frac{\pi}{k^{2}} \sum_{\mathrm{J}} g_{\mathrm{J}} \sum_{\substack{\text { incident } \\ \text { channels } \\ \mathrm{c}}}\left(1-\sum_{\substack{\mathrm{all} \\ \text { channels } \\ \mathrm{c}^{\prime}}}\left|\mathrm{w}_{\mathrm{c} \mathrm{c}^{\prime}}^{\mathrm{J}^{\prime}}\right|^{2}\right)
$$

Note that the total cross section is the sum of the other three:

$$
\sigma^{\text {total }}=\sigma^{\text {elastic }}+\sigma^{\text {reaction }}+\sigma^{\text {capture }} \text {. }
$$

In Eq. (IV.6) through (IV.9), $g_{J}$ is the spin statistical factor

$$
g_{J}=\frac{2 J+1}{2(2 I+1)}
$$

where $I$ is the target spin. The quantity $k$ is the neutron momentum in the center-of-mass system, related to laboratory kinetic energy $E$ by

$$
E-\frac{\hbar^{2}}{2 M c^{2}} k^{2}
$$

where $M$ is given by

$$
\frac{1}{M}=\frac{1}{M_{\text {neutron }}}\left(\frac{M_{\text {neutron }}+M_{\text {target }}}{M_{\text {target }}}\right)^{2} \text {. }
$$

Multiple-scattering corrections are not included in the capture cross sections; it is the authors' intention to introduce these corrections in the near future. 


\section{IMPLEMENTATION OF MULTILEVEL R-MATRIX THEORY}

The implementation of multilevel R-matrix theory with Doppler- and resolution-broadening was borrowed from the least squares multilevel R-matrix code MULTI, developed by George Auchampaugh (AU74). The coding was extensively modified for clarity, for easier amendment and additions, and for greater compatibility with the PDP-10 computer system at ORELA. However, the basic design of this portion of the computer code SAMMY is exactly that which was first implemented in MULTI. (The code name SAMMY had its origin here: $\quad$ SAM = Severely Altered MULTI.)

Generation of theoretical cross sections and derivatives in SAMMY, as in MULTI, is accomplished as follows: The user specifies which of the physical parameters $E_{\lambda}, \Gamma_{\lambda c}, \Gamma_{\lambda}^{\gamma}$ are to be varied. These parameters are converted to "u-parameters" vi.a

$$
\begin{aligned}
& u\left(E_{\lambda}\right)= \pm \sqrt{\left|E_{\lambda}\right|} \text {, where the negative sign is chosen if } E_{\lambda}<0, \\
& u\left(\Gamma_{\lambda c}\right)=\gamma_{\lambda c} \text { where } \Gamma_{\lambda c}=2 \gamma_{\lambda c}^{2} P_{\ell}, \\
& u\left(\Gamma_{\lambda}^{\gamma}\right)=\alpha_{\lambda} \text { where } \Gamma_{\lambda}^{\gamma}=2 \alpha_{\lambda}^{2} .
\end{aligned}
$$

(Note that $\gamma_{\lambda}$ and $\alpha_{\lambda}$ may be either positive or negative.) It is the u-parameters on which Bayes' equations operate.

To solve Bayes! equations, it is necessary to know both the cross section and the derivative of the cross section with respect to each u-parameter, evaluated at every energy for which input data is available. The chain rule is used to evaluate partial derivatives:

$$
\frac{\partial \sigma}{\partial i_{i}}=\sum_{\substack{\mu \leq \nu \\ \omega \leq \tau}} \frac{\partial R_{\mu \nu}}{\partial n_{i}} \frac{\partial W_{\omega \tau}}{\partial R_{\mu \nu}} \frac{\partial \sigma}{\partial W_{\omega \tau}}
$$


where the index $\mathrm{J}$ has been suppressed, since it is fixed for a given $u$. The restricted sums $(\mu \leq \nu, \omega \leq \tau)$ result from the symmetry of $R$ and $W$. In Eq. (IV.1), the R-matrix is given as

$$
\mathrm{R}_{\mu \nu}=\sum_{\lambda} \frac{{ }_{\lambda \mu}{ }^{\gamma} \lambda \nu}{\mathrm{E}_{\lambda}-\mathrm{E}-i \alpha_{\lambda}^{2}}
$$

from which the derivative of $R$ with respect to the parameters can be found:

$$
\begin{aligned}
& \frac{\partial \operatorname{Re} R_{\mu \nu}}{\partial \sqrt{E_{\lambda}}}-\left[2 \gamma_{\lambda \mu} \gamma_{\lambda \nu} \sqrt{E_{\lambda}}\right]\left[\left\{-\left(E_{\lambda}-E\right)^{2}+\left(\alpha_{\lambda}^{2}\right)^{2}\right\} / D_{\lambda}^{2}\right] \\
& \frac{\partial \operatorname{Im} R_{\mu \nu}}{\partial{ }^{\prime} E_{\lambda}}=\left[-4 \gamma_{\lambda \mu} \gamma_{\lambda \nu} \sqrt{E_{\lambda}}\right]\left[\left(E_{\lambda}-E\right) \alpha_{\lambda}^{2} / D_{\lambda}^{2}\right] \\
& \frac{\partial \operatorname{Re} R_{\mu \nu}}{\partial \alpha_{\lambda}}=\left[\begin{array}{llll}
-4 & \gamma_{\lambda \mu} & \gamma_{\lambda \psi} & \alpha_{\lambda}
\end{array}\right]\left[\left(E_{\lambda}-E\right) \alpha_{\lambda}^{2} / D_{\lambda}^{2}\right] \\
& \frac{\partial \operatorname{Im} R_{\mu \nu}}{\partial \alpha_{\lambda}}=\left[\begin{array}{lll}
2 \gamma_{\lambda \mu} & \gamma_{\lambda \nu} & \left.\alpha_{\lambda}\right]
\end{array}\left[\left\{\left(E_{\lambda}-E\right)^{2}-\left(\alpha_{\lambda}^{2}\right)^{2}\right\} / D_{\lambda}^{2}\right]\right. \\
& { }_{\partial{ }_{\lambda \mu}}^{\partial R_{\Omega} R_{\mu \nu}}=\left[\gamma_{\lambda \nu}\left(1+\delta_{\mu \nu}\right)\right]\left[\left(E_{\lambda}-E\right) / D_{\lambda}\right] \\
& \frac{\partial \lim k_{\mu \nu}}{\partial \gamma_{\mu \nu}}=\left[\gamma_{\lambda \nu}\left(1+\delta_{\mu \nu}\right)\right]\left[\alpha_{\lambda}^{2} / D_{\lambda}\right]
\end{aligned}
$$

where

$$
\mathrm{D}_{\lambda}=\left(\mathrm{E}_{\lambda}-\mathrm{E}\right)^{2}+\alpha_{\lambda}^{\prime \prime} \quad
$$


In each of Eqs. $(\mathrm{V} .6)-(\mathrm{V} .8)$, the first square bracket contains an energy-independent factor; in the code SAMMY, this factor is evaluated outside the energy-100p in subroutine $B A B B$ and is stored as BR( $i, \mu \nu)$ for the derivative of the real part of $R_{\mu \nu}$ with respect to the $i^{\text {th }}$ parameter, and $B I(i, \mu \nu)$ for the derivative of the imaginary part of $R_{\mu \nu}$. The quantity in the second square bracket is energy-dependent but channel-independent. Therefore, it must be generated for each energy and is temporarily stored as UPR( $i$ ) and UPI( $i$ ) in subroutine ABPART.

From Eq. (IV.4), W may be written in terms of $R$ as

$$
\mathrm{W}_{\omega \tau}=\delta_{\omega \tau}\left(1-\frac{2 \mathrm{iP}}{\mathrm{L}_{\omega}}\right)+2 i \frac{\sqrt{\mathrm{P}_{\omega}}}{\mathrm{L}_{\omega}} \mathrm{Y}_{\omega \tau} \frac{\sqrt{\mathrm{P} \tau}}{\mathrm{L}_{\tau}}
$$

where we have set

$$
Y_{\omega \tau}=\left[\left(\frac{1}{L}-R\right)^{-1}\right]_{\omega \tau}
$$

In Appendix $A$, we show that the derivative of $Y$ with respect to $R$ is given by

$$
\frac{\partial Y_{\omega \tau}}{\partial R_{\mu \nu}}=Y_{\omega \mu} Y_{\nu \tau}+Y_{\omega \nu} Y_{\mu \tau}\left(I-\delta_{\mu \nu}\right)
$$

Substitution of Eq. (V.12) into the derivative of Eq. (V.10) gives 


$$
\frac{\partial W_{\omega \tau}}{\partial R_{\mu \nu}}=2 i \frac{\sqrt{P_{\omega}}}{L_{\omega}} \cdot\left[Y_{\omega \mu} Y_{\nu \tau}+Y_{\omega \nu} Y_{\mu \tau}\left(1-\delta_{\mu \nu}\right)\right] \frac{\sqrt{P_{\tau}}}{L_{\tau}} \cdot \quad(V \cdot 13)
$$

The derivative of the cross section with respect to $W$ differs for each type of cross section. For total, it is

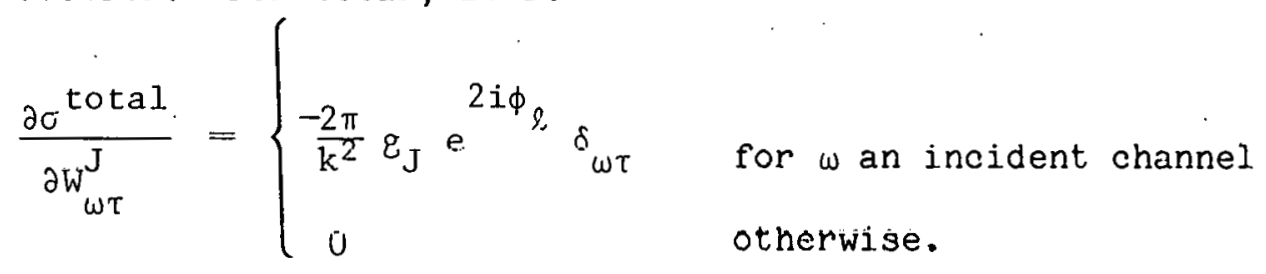

For elastic scattering, the derivative is

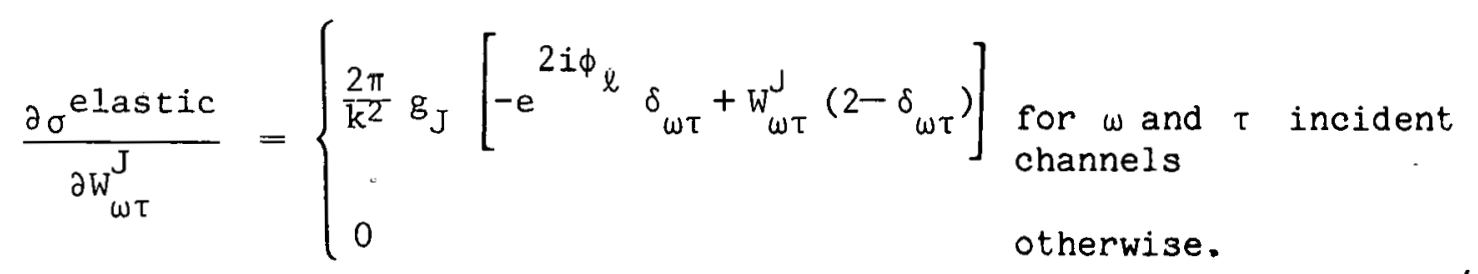

For the reaction cross section, we must have a $S \tau$, which gives for the derivative

$$
\frac{\partial \sigma^{\text {reaction }}}{\partial W_{\omega \tau}^{\mathrm{J}}}= \begin{cases}\frac{2 \pi}{k^{2}} g_{\mathrm{J}} \mathrm{W}_{\omega \tau}^{\mathrm{J}} & \text { for } \omega \text { an inoident ohanncl } \\ & \text { and } \tau \text { an exit channel } \\ 0 & \text { otherwise. }\end{cases}
$$

Finally, the derivative of the capture cross section is

$$
\frac{\partial \sigma^{\text {capture }}}{\partial W_{\omega \tau}^{J}}= \begin{cases}-\frac{2 \pi}{k^{2}} g_{J} W_{\omega \tau}^{J} & \begin{array}{l}
\text { for at least one of } \omega \text { and } \tau \text { an } \\
\text { entrance channel } \\
0
\end{array} \quad \text { otherwise. }\end{cases}
$$


The partial derivatives $G^{i}{ }^{i}$, defined in $\mathrm{Eq}$. (II.7) and required in Bayes' equations, are then found from Eq. (V.4), using Eqs. (V.6) through (V.9) for $\frac{\partial R}{\partial u}$, Eq. (V.13) for $\frac{\partial W}{\partial R}$, and Eqs. (V.14) through $(V .17)$ for $\frac{\partial \sigma}{\partial W}$, all evaluated at energy $E^{i}$. Subroutine PARSH oversees the evaluation of the partial derivatives and the cross sections.

To avoid problems arising from the computer's limited precision, and to minimize computing time, partial derivatives for non-s-wave resonances are truncated to zero far away from the resonance. The working definition of "far away" is 20 times the sum of the partial widths for that resonance, i.e., far beyond the region where a resonance can produce any noticeable effect.

Doppler- and resolution-broadening of the cross sections in SAMMY is accomplished in precisely the same fashion as in MULTI; in addition, partial derivatives are broadened in SAMMY (but not in MULTI). An auxiliary energy array is set up in subroutine ESCALE, including all (primary) energies at which input data are provided plus enough additional points to ensure proper broadening (a minimum of nine points across the width of each resonance, and extra points at the beginning and end of the energy range). Cross sections and partial derivatives are generated at each auxiliary energy, as described above. Doppler-broadened cross sections and partial derivatives are calculated at each auxiliary energy by forming linear combinations of the unbroadsned values, approximating a Gaussian convolution. Total cross sections are then converted to transmissions (with appropriate conversion of the partial derivatives), and resolution-broadened cross sections (or transmissions) and partial derivatives are formed at each primary energy from linear combinations of the Doppler-broadened values. The 
resolution-broadening function can be either Gaussian, exponential, or a combination of the two. Finally, transmissions are converted to total cross-sections if input data are in that form. Subroutine BRØADN performs the broadening operations. For details regarding the precise form of the broadening functions, the reader is referred to the documentation of MULTI $(\mathrm{AU} 74)$. 


\section{CALCULATIONS AND COMPARISONS}

The computer code SAMMY has been extensively fine-tuned and debugged via test calculations and via comparisons with the least-squares multilevel R-matrix code MULTI (AU74). Results of four such calculations are reported here. The first example is a repeat analysis of $\mathrm{Ni}^{60}$ transmission data, including direct comparison of MULTI and SAMMY results. The second and third examples use artificial data to demonstrate how off-diagonal data covariances can be used to decouple a p-wave resonance from an improperly fitted s-wave and to offset the effects of improper background subtraction. The final example illustrates the extent to which a sequential analysis of (uncorrelated) data sets is equivalent to a simultaneous analysis, in the extreme case where data from an s-wave resonance is divided near the resonance energy.

\section{1. $\mathrm{Ni}^{60}$ Transmission Data}

Preliminary results from C. Perey's (PE80C) MULTI analysis of Harvey's (HA80) $\mathrm{Ni}^{60}$ transmission data were used as starting values for a SAMMY analysis of that data. Data consisted of 2593 total cross sections and uncertainties in the energy range from 10 to $550 \mathrm{keV}$. Included were 212 resonances, of which 189 were within the data range (the others being dummies inserted in order to reproduce the backgrounds). Neutron widths $\left(\Gamma_{n}\right)$ for each of these 189 resonances were varied; all resonance energies and gamma-ray widths $\left(\Gamma_{\gamma}\right)$ were held fixed. Initial uncertainties on the neutron widths were arbitrarily set at $10 \%$ of the width. 
A sampling of the results from this analysis is shown in Table VI. 1. In general, SAMMY results (Column B) did not deviate far from the MULTI results (Column A) used as starting values for SAMMY. Theoretical curves generated from the two sets of parameters are rarely distinguishable.

A second SAMMY analysis of this same data was performed, using arbitrary starting values of $\Gamma_{n}$; these values were in the range 0.5 to 1.5 times the original starting values. Partial results from this analysis are also shown in Table VI.1. Results (Column C) are generally in closer agreement with both MULTI results (Column A) and previous SAMMY results (Column B) than with the starting values (Column D). One notable exception is parameter number 121; in this case, however, the output uncertainty is $10 \%$ of the value for $\Gamma_{n}$. Since $10 \% \Gamma_{n}$ was given as the starting value for the uncertainty, this result indicates that the parameter is unaffected by the data.

A modest attempt was made to use these same starting values (Column D in Table VI.1) as input to a MULTI analysis (five iterations only) of this data, though by no means was a complete analysis performed. Preliminary results are shown in Column E. From these partial results, it appears that MULTI has more difficulty than SAMMY in arriving at reasonable answers when starting values are far off. MULTI could, of course, do better were it allowed to iterate to convergence.

It should be noted that SAMMY results are obtained in a more straightforward fashion than MULTI results. With SAMMY, it is necessary to divide the almost 2600 data points into 24 data sets, analyzing each data set in turn but using output from one as input for the next. All 189 parameters are varied all the time, though of course most are virtually unaffected by 
TARLE VI.1. COMPARISON OF MULTI AND SAMMY RESULTS FOR NI 60 TrANSMISS ION IOATA

\begin{tabular}{|c|c|c|c|c|c|c|c|c|c|}
\hline \multirow{2}{*}{$\begin{array}{l}\text { Parameter } \\
\text { Number } \\
\text { s } 1 / 2\end{array}$} & \multirow[t]{2}{*}{$\begin{array}{l}\text { Energy of } \\
\text { Resoniance } \\
\text { (keV) }\end{array}$} & \multirow[t]{2}{*}{$\begin{array}{l}\quad A . \\
\text { MULTI } \\
\text { Value } \\
\text { of } \Gamma_{n} \\
(e v)\end{array}$} & $\begin{array}{l}\text { SAMMY Va } \\
\text { Usting Co } \\
\text { Starting }\end{array}$ & $\begin{array}{l}\text { lue of } \Gamma_{n} \\
\text { lumn A for } \\
\text { VaJue }\end{array}$ & \multicolumn{2}{|c|}{$\begin{array}{l}\text { SAMMY } \\
\text { Results for } \\
\Gamma_{\mathrm{n} \text { Using }} \\
\text { Arbitrary } \\
\text { Starting Vajue }\end{array}$} & \multirow[t]{2}{*}{$\begin{array}{l}\text { Starting Valun } \\
\text { for Col } C \text { alud } F\end{array}$} & \multicolumn{2}{|c|}{$\begin{array}{l}\text { E. } \\
\text { MUt.TI Fartial } \\
\text { Resultis ror. } \Gamma_{\mathrm{n}} \\
\text { Uaing Startlur } \\
\text { Vajues in Col }\end{array}$} \\
\hline & & & & & & \multirow[b]{2}{*}{ Errer } & & \multirow{3}{*}{$\frac{\text { Yalue }}{610.144}$} & \multirow{3}{*}{ Errod } \\
\hline & & & Value & Error & Value & & & & \\
\hline 14 & 251.90 & 556.00 & 536.03 & 3.94 & 547.29 & 4.02 & 500.00 & & \\
\hline 15 & 256.00 & 810.00 & 792.64 & 5.53 & 805.70 & 5.73 & 1000.00 & 982.00 & 3.65 \\
\hline 16 & 257.60 & 1840.00 & 1800.20 & 6.54 & 1846.10 & 6.75 & 2000.00 & 2127.20 & 5.95 \\
\hline 17 & 278.90 & 222.00 & 213.78 & 2.34 & 218.90 & 2.36 & 250.00 & 261.511 & 2.03 \\
\hline 18 & 291.80 & 122.00 & 118.40 & 2.73 & 120.33 & 2.71 & 100.00 & 123.80 & 1.33 \\
\hline 19 & 316.90 & 2840.00 & 2715.50 & 8.16 & 2794.50 & 8.22 & 2500.00 & 2960.20 & 8.13 \\
\hline 20 & 325.38 & 6805.00 & 6924.80 & 13.64 & 6877.10 & 13.74 & 5000.00 & 6952.20 & 11.53 \\
\hline 21 & 338.34 & 3370.00 & 3419.20 & 12.32 & 3402.60 & 12.53 & 2500.00 & $3 ? 91.90$ & 12.03 \\
\hline \multicolumn{10}{|l|}{$r 1 / 2$} \\
\hline 100 & 252.98 & 240.000 & 247.230 & 2.915 & 250.240 & 2.929 & 250.000 & 298.200 & 2.369 \\
\hline 101 & 254.26 & 22.000 & 19.303 & 0.600 & 18.800 & 0.562 & 20.000 & 22.068 & 0.5115 \\
\hline 102 & 256.18 & 34.000 & 28.153 & 1.778 & 32.342 & 2.011 & 50.000 & 20.791 & $0.8 ?$ \\
\hline 103 & 257.69 & 15.000 & 22.081 & 0.989 & 17.009 & 0.784 & 10.000 & 17.383 & 0.17 \\
\hline 104 & 258.15 & 21.000 & 13.287 & 0.995 & 15.823 & 1.076 & 25.000 & 24.905 & 0.603 \\
\hline 105 & 260.72 & 12.000 & 49.430 & 1.531 & 48.774 & 1.579 & 50.000 & 35.618 & 2.526 \\
\hline 106 & 263.00 & 33.000 & 32.056 & 0.857 & 25.389 & 0.688 & 25.000 & 21.723 & 0.308 \\
\hline 107 & 265.85 & 55.000 & 53.011 & 1.360 & 52.306 & 1.342 & 50.0 no & 58.199 & $0.9^{\prime 16}$ \\
\hline 108 & 276.95 & 15.000 & 14.396 & 0.783 & 18.561 & 0.941 & 20.000 & 33.800 & 2.128 \\
\hline 109 & 278.08 & 375.000 & 362.550 & 2.618 & 363.600 & 2.622 & 500.000 & 1103.530 & 2.516 \\
\hline 110 & 280.02 & 125.000 & 122.580 & 2.078 & 120.880 & 2.058 & $100: 000$ & $13^{14}: 350$ & 1.625 \\
\hline 111 & 282.00 & 10.000 & 8.132 & 0.508 & 8.385 & 0.516 & 10.000 & 32.036 & 2.1410 \\
\hline 112 & 288.10 & 4.000 & 2.002 & 0.201 & 2.598 & 0.250 & 5.000 & 1.298 & 3.715 \\
\hline 113 & 290.50 & 32.000 & 22.013 & 1.124 & 26.920 & 1.277 & 50.000 & 43.403 & 1.246 \\
\hline 111 & 292.50 & 129.000 & 134.710 & 2.664 & 133.400 & 2.615 & 100.000 & 157.070 & 1.1166 \\
\hline 115 & 294.20 & 10.000 & 8.432 & 0.1178 & 7.411 & 0.412 & 8.000 & 14.254 & 5.236 \\
\hline 116 & 294.70 & 15.000 & 10.493 & 0.653 & 8.870 & 0.548 & 10.000 & 15.491 & 3.309 \\
\hline 117 & 295.110 & 133.000 & 115.650 & 1.871 & 119.290 & 1.880 & 100.000 & 151.140 & 1.943 \\
\hline 118 & 302.00 & 10.000 & 6.830 & 0.472 & 7.782 & 0.476 & 12.000 & 3.166 & 5.093 \\
\hline 119 & 306.50 & 385.000 & 351.580 & 3.430 & 357.210 & 3.495 & 250.000 & 122.260 & 2.762 \\
\hline 120 & 311.30 & 20.000 & 15.311 & 0.901 & 17.267 & 1.093 & 25.000 & 13.1133 & 1.738 \\
\hline 121 & 313.40 & 7.000 & 7.000 & 0.700 & 5.000 & 0.500 & 5.000 & 1.601 & 3.123 \\
\hline 122 & 321.40 & 17.000 & 17.481 & 0.820 & 18.273 & 0.854 & 20.000 & 16.247 & 2.403 \\
\hline 123 & 328.90 & 37.500 & 37.119 & 1.614 & 40.721 & 1.650 & 50.000 & 110.152 & 1.111 \\
\hline $12 i$ & 335.93 & 145.000 & 146.050 & 2.186 & 132.460 & 2.211 & 100.000 & 137.1180 & $1.11 ? 7$ \\
\hline 17.5 & 339.75 & 10.000 & 6.705 & 0.729 & 11.596 & 1.291 & 20.000 & 2.2 .31 & 3.150 \\
\hline
\end{tabular}


TABLE II. ". TOMPARIJCN OF MLLI IND SAMMY SESULTS FOR MI 60 TRANSYISSION JATA (CONT:O)

\begin{tabular}{|c|c|c|c|c|c|c|c|c|c|}
\hline \multirow{2}{*}{$\begin{array}{l}\begin{array}{l}\text { Paramiter } \\
\text { Numbe: }\end{array} \\
\text { P } 1 / 2 \text { (Ccn }\end{array}$} & \multirow{2}{*}{$\begin{array}{l}\begin{array}{l}\text { Energy of } \\
\text { Resonanze } \\
\text { (keV) }\end{array} \\
\text { 'd) }\end{array}$} & \multirow[t]{2}{*}{$\begin{array}{l}\text { A. } \\
\text { MULzI } \\
\text { Vaige } \\
\text { of }-n \\
\text { (ev! }\end{array}$} & \multicolumn{2}{|l|}{$\begin{array}{l}\text { SAMMY Jal } \\
\text { Using Col } \\
\text { Starting }\end{array}$} & $\begin{array}{l}\text { SAMMY } \\
\text { Resulis } \\
\Gamma_{\mathfrak{n}} \text { Usirg } \\
\text { Arbitrary } \\
\text { Starting }\end{array}$ & $\begin{array}{l}\text { or } \\
\text { Vaile }\end{array}$ & \multirow[t]{2}{*}{$\begin{array}{l}\text { Starting value } \\
\text { for } \operatorname{Col} C \text { and } z\end{array}$} & \multicolumn{2}{|c|}{$\begin{array}{l}\text { シ. } \\
\text { MULII Partial } \\
\text { Resuits for } \Gamma_{n} \\
\text { Using Starting } \\
\text { Values in Col D }\end{array}$} \\
\hline & & & & & & & & & \\
\hline $\begin{array}{l}126 \\
127 \\
128 \\
129\end{array}$ & $\begin{array}{l}34 \cdot .25 \\
343.00 \\
348.05 \\
349.00\end{array}$ & $\begin{array}{r}120.000 \\
280.000 \\
300.000 \\
30.000\end{array}$ & $\begin{array}{r}115.590 \\
235 .: 90 \\
82.899 \\
23.679\end{array}$ & $\begin{array}{l}\frac{10001}{3.750} \\
4.238 \\
2.421 \\
1.317\end{array}$ & $\begin{array}{r}111.210 \\
228.030 \\
75.670 \\
24.344\end{array}$ & $\begin{array}{l}3.077 \\
4.125 \\
2.353 \\
1.450\end{array}$ & $\begin{array}{r}100.000 \\
250.000 \\
50.000 \\
25.000\end{array}$ & $\begin{array}{r}131.870 \\
305.290 \\
131.560 \\
45.610\end{array}$ & $\begin{array}{l}2.040 \\
3.745 \\
1.181 \\
i .042\end{array}$ \\
\hline \multicolumn{10}{|l|}{$P 3 / 2$} \\
\hline $\begin{array}{l}157 \\
158\end{array}$ & $\begin{array}{l}334.01 \\
342.40\end{array}$ & $\begin{array}{r}T 15.000 \\
33.000\end{array}$ & $\begin{array}{r}115.630 \\
29.612\end{array}$ & $\begin{array}{l}1.394 \\
1.185\end{array}$ & $\begin{array}{r}104.940 \\
36.500\end{array}$ & $\begin{array}{l}1.409 \\
1.277\end{array}$ & $\begin{array}{r}100.000 \\
50.000\end{array}$ & $\begin{array}{r}122.520 \\
43.446\end{array}$ & $\begin{array}{l}1.810 \\
0.565\end{array}$ \\
\hline \multicolumn{10}{|l|}{ D $3 / 2$} \\
\hline $\begin{array}{l}165 \\
166 \\
167 \\
168 \\
169 \\
170 \\
171\end{array}$ & $\begin{array}{l}230.05 \\
269.00 \\
282.38 \\
297.20 \\
300.30 \\
307.25 \\
327.30\end{array}$ & $\begin{array}{r}50.000 \\
45.000 \\
: 38.000 \\
73.500 \\
25.000 \\
: 04.000 \\
12.000\end{array}$ & $\begin{array}{r}49.474 \\
43.615 \\
138 . .20 \\
68.256 \\
18.0184 \\
107.910 \\
7.585\end{array}$ & $\begin{array}{l}0.589 \\
0.731 \\
1.082 \\
0.379 \\
0.504 \\
1.368 \\
0.0618\end{array}$ & $\begin{array}{r}48.898 \\
45.234 \\
136.040 \\
66.086 \\
i 7.227 \\
107.510 \\
6.793\end{array}$ & $\begin{array}{l}0.584 \\
0.755 \\
1.075 \\
0.858 \\
0.484 \\
1.577 \\
0.543\end{array}$ & $\begin{array}{r}40.000 \\
50.000 \\
i 00.000 \\
50.000 \\
20.000 \\
i 00.000 \\
i 0.000\end{array}$ & $\begin{array}{r}39.350 \\
49.477 \\
107.430 \\
46.626 \\
18.909 \\
99.714 \\
3.449\end{array}$ & $\begin{array}{l}0.434 \\
0.017 \\
0.228 \\
0.550 \\
0.272 \\
0.116 \\
0.109\end{array}$ \\
\hline
\end{tabular}


any given data set. Results thus obtained are valid and consistent over the entire energy region. Total time required for the SAMMY analysis was less than one week.

In contrast, the initial MULTI analysis required over six months of effort; this included searches on both energies and widths. Data were divided into seven data sets (more points per data set are allowed since MULTI need not store covariance matrices), each of which was analyzed independently. Frequent intervention and decision-making were required from the physicist doing the analysis, in order to ensure consistency between the various data sets. For our MULTI "analysis" (Column $E$ in Table VI.1), the intention was to see how well MULTI could perform given only slightly more user-intervention than SAMMY requires. Only the $\Gamma_{n}$ for resonances within the data set being analyzed could be varied, first because MULTI accepts a maximum of .150 search parameters, but more importantly because a search on "outside" parameters often yields drastic (and unrealistic) changes in the values of those parameters. Updated parameters from five iterations on one data set were used as input for the next data set, with the initial value being substituted when unphysical values were output. The "analysis" was discontinued after the fifth data set, since output values were too far afield to have any hope of reaching reasonable results from the two remaining data sets.

Parameter uncertainties presented in Table VI. 1 may be viewed as unrealistically small. As discussed in Section II, this is because we have improperly assumed the data points to be independent, rather than included an off-diagonal covariance matrix to describe corrections made to the data and approximations made in generating the theoretical values. Correctly 

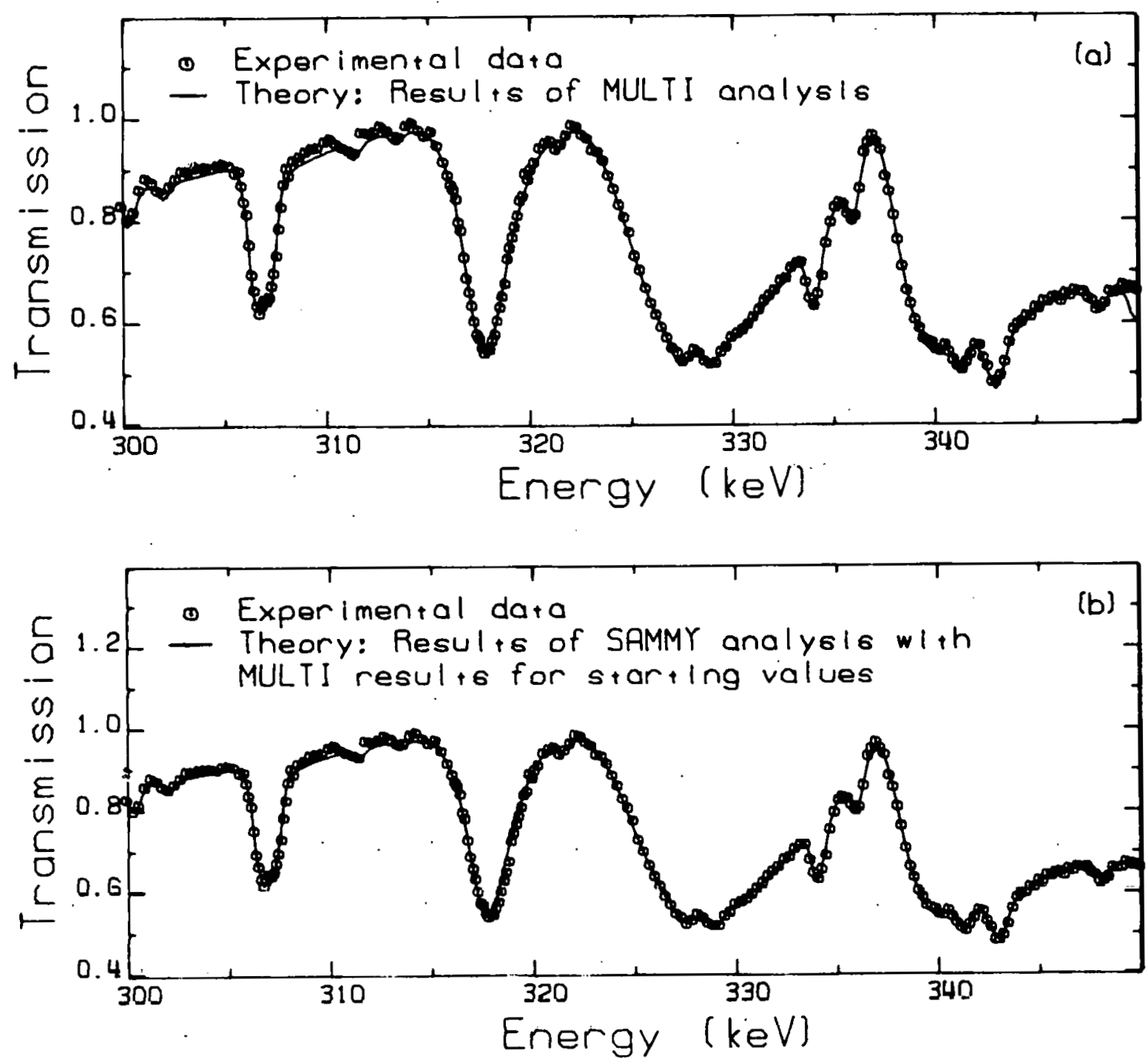

Fig. VI.1. Theoretical curves resulting from MIIT.TT and SAMMY analyses of $\mathrm{Ni}^{60}$ data (HA80), corresponding to the five parameter sets listed in Table VI.1. Part a uses parameters generated by the MULTI analysis of Perey (PE80c) and part $b$ those from the first SAMMY analysis. Curves shown in part $c$ are from the second SAMM analysis and part $e$ from the second MULTI analysis, both of which used the arbitrary starting parameters whose curve is shown in part $d$. 

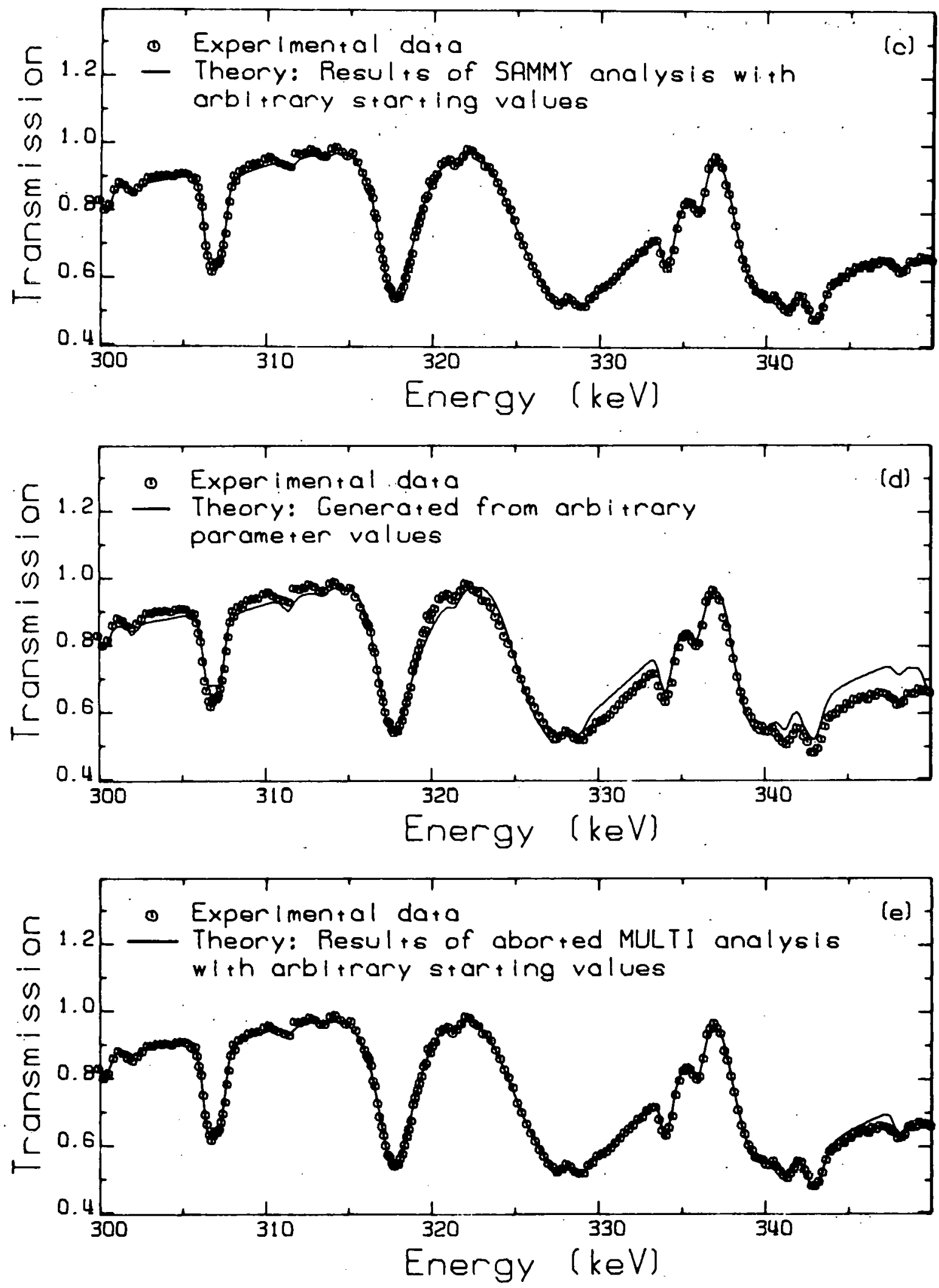

Fig. VI.1. (Cont'd). 
including these effects would produce more reasonable values for data uncertainties.

One might naively expect the two SAMMY results (columns $B$ and $C$ of the table) to agree to within the quoted uncertainties. This does not happen for two reasons: First, the quoted uncertainties are unrealistically small, as discussed above. Secondly, the different starting values for the two runs do affect the resulting parameter values as can be seen directly from Bayes' equations. However, the different starting values produce only second-order effect on the uncertainties, especially when data uncertainties are much smaller than input parameter uncertainties, as they are in this example. Thus parameter values will differ slightly with different starting values, but parameter uncertainties will not.

Theoretical curves generated by using the five parameter sets corresponding to the columns A through E of Table VI.1 are given in Figure VI.1. For clar1ty, only a portion of the energy range is shown. Note that the complete MULTI analysis (part a) and both SAMMY analyses (parts $b$ and c) provide reasonable fits to the experimental data, while the seond MULII analysis (part e) appears more strongly affected by its starting values (part d) than by the data.

2. The Effect of Improperly Fitted S-Wave on Neighboring P-Wave Resonance Artificial data were generated in order to study the effect of offdiagonal data covariances in fitting a small p-wave located near the peak of a large s-wave resonance. Elastic scattering "data" for 123 energies were generated from the parameters shown in Column A of Table VI.2. No random noise was added to the data, so that these values are, in fact, exact. An arbitrary $1 \%$ uncertainty was assigned to each data point. 
TABLE VI.2. PARAMETER VALUES FOR EXAMPLE NUMBER 2. DECOUPLING P-WAVE RESONANCE FROM AN IMPROPERLY FITTED S-WAVE BACKGROUND

\begin{tabular}{|c|c|c|c|c|c|}
\hline & $\begin{array}{l}\text { Exact } \\
\text { Values }\end{array}$ & $\begin{array}{l}\text { Input } \\
\text { Param- } \\
\text { eters }\end{array}$ & $\begin{array}{l}\text { Results } \\
\text { from } \\
\text { MULTI }\end{array}$ & $\begin{array}{l}\quad \quad \text { D. } \\
\text { Results } \\
\text { from } \\
\text { SAMMY } \\
\text { without } \\
\text { Off-Diagonal } \\
\text { Covariances }\end{array}$ & $\begin{array}{l}\quad \text { E. } \\
\text { Results } \\
\text { from } \\
\text { SAMMY } \\
\text { with } \\
\text { Off-Diagonal } \\
\text { Covariances }\end{array}$ \\
\hline$E_{\text {res }}(S)$ & $156.00 \mathrm{keV}$ & $156.00 \mathrm{keV}$ & & & \\
\hline$\Gamma_{n}(S)$ & $3000.0 \mathrm{eV}$ & $3200.0 \mathrm{eV}$ & & & \\
\hline$E_{\text {res }}(P)$ & $160.00 \mathrm{keV}$ & $160.00 \mathrm{keV}$ & $159.99 \pm 0.0004$ & $160.000 \pm 0.003$ & $160.000 \pm 0.00$ \\
\hline$\Gamma_{n}(P)$ & $50.000 \mathrm{eV}$ & $55: 000 \mathrm{eV}$ & $84.894 \pm 0.832$ & $42.954 \pm 0.945$ & $50.012 \pm 1.149$ \\
\hline
\end{tabular}


It is assumed that the s-wave parameters are fixed (perhaps from earlier experiments) at the values shown in Column B of Table VI.2. The "known" value for $\Gamma_{\mathrm{n}}$ is noticeably different from the "exact" value, as shown by the discrepancy between "data" and the "theoretical" curve in Fig. VI.2, but is nevertheless fixed for this calculation. In other words, we have deliberately. introduced a systematic error in the theoretical values. The purpose of this calculation is to obtain the hitherto "unknown" p-wave parameters, starting from arbitrary initial values, and thereby to illustrate how the effect of such systematic errors can be incorporated in SAMMY analyses.

Three distinct calculations were performed, each using all 123 data points. The first, using program MULTI, gives the erroneous results shown in Column $C$ of Table VI.2. This is to be expected, since systematic errors must be handled external to MULTI and we have not done so. "The second calculation, using SAMMY, treats each data point as independent, and leads to a value for the p-wave $\Gamma_{n}$ (see Column $D$ of the table) which does allow the theory to reproduce the data at the $p$-wave resonance. This value for $\Gamma_{n}$ differs from the exact value, since the calculation attempts to fit both the p-wave peak and the s-wave background by adjusting only the one parameter. How well this is accomplished is illustrated in Fig. VI.2b, in which only the neighborhood of the p-wave resonance is shown.

The third calculation makes use of the "decoupling" procedure in SAMMY, described in Section III.3, to incorporate the effect of the systematic theoretical error. A constant on- and off-diagonal term is added to the original (diagonal) data covariance matrix in the neighborhood of the pwave resonance; this allows the theoretical values to deviate from 

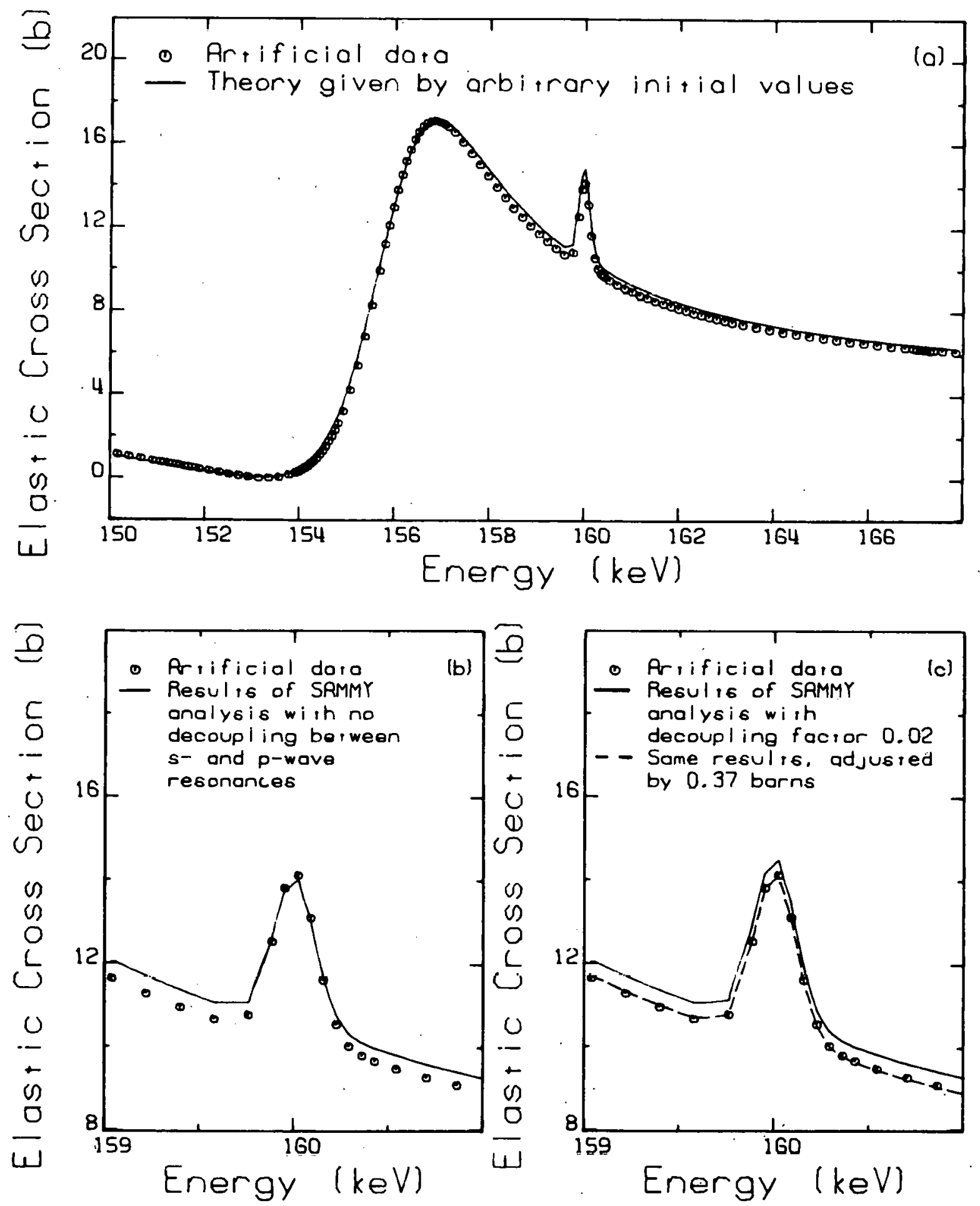

Fig. VI.2. Artificial data used to study the effect of an improperly fitted s-wave on a neighboring $p$-wave resonance. The theoretical curve in part $\dot{a}$ is generated from the input parameters. The theoretical curve in part $b$ results from the SAMMY calculation with no decoupling between the $s-$ and p-wave resonances; only the energy region near the $\mathrm{p}$-wave is shown, though the entire range was used for the calculation. The solid curve shown in part $c$ results from the SAMMY calculation with a decoupling parameter of 0.02 ; the dashed curve is the solid curve adjusted by 0.37 barns. 
"experimental" values in a coherent fashion. Results of this calculation are in excellent agreement with the exact values, as shown by comparing Columns $A$ and $E$ of Table VI.2. Part $c$ of Fig. VI.2 illustrates the degree to which these values reproduce this data: The upper curve was produced directly from the parameter values given by the calculation. The lower curve is the upper curve displaced by 0.37 barns, and falls directly on each data point.

It is interesting to note that the precise value chosen for the offdiagonal term is not critical, as long as it is big enough. The calculation reported here used the value 0.02 , which is the same order of magnitude as the diagonal terms of the data covariance matrix. Values of 0.20 and 2.00 yielded equivalent results; the value 0.002 yielded ${ }^{n} n$ smaller than the exact result but still larger than that obtained with no offdiagonal covariances. Thus, it appears that one should take care to accurately estimate the decoupling term.

\section{Errors in Background Subtraction}

Other artificial data were generated to consider the problem of background subtraction. Elastic cross sections from two s-wave and three pwave resonances were evaluated at 123 data points; the maximum cross section was approximately 16 barns. To these values was added a constant background of $2.00 \pm .02$ barns, with the error normally distributed. Poisson-type noise was then added, and the results were taken as the raw "experimental" data. Data uncertainties ranged from 0.2 to 0.6 , so that diagonal members of the covariance matrix were in the range from 0.04 to 0.40. To simulate improper background subtraction, ne background was subtracted from the raw data. 
Three separate analyses were again performed; results are tabulated in Table VI.3. Although many codes handle this kind of problem by adjusting a background (see, e.g., SIØB, (DE78)), neither MULTI nor SAMMY is equipped to do so. Thus the MULTI analysis (Column $C$ of the table) strayed far from the "exact" values (Column A), as did the first SAMMY analysis which used a diagonal data covariance matrix (Column D). However, when a constant value of 0.04 was added to the data covariance matrix in SAMMY, results (Column E) are in good agreement with the exact values. Thus SAMMY can be used to obtain reasonable values for resonance parameters when the background level is not well determined and it is so communicated to the code.

Fig. VI.3a shows the curve generated from the results of the first SAMMY analysis. Note that the shape of the theoretical curve is considerably distorted from the shape of the data. Part $b$ of the figure shows the curve generated from the results of the SAMMY analysis with off-diagonal data covariances; the solid curve is exactly as generated, and the dashed curve is displaced by 2.00 barns.

\section{Simultaneous vs. Sequential Analysis of S-Wave}

The ability to perform a sequential analysis of independent data sets, and obtain results which are equivalent to a simultaneous analysis of that same data, is a major strength of Bayes' method and represents a significant improvement over the sequential (and therefore separate) analyses performed with conventional least-squares methods. Because the derivation of Bayes' equations from Bayes' theorem involves several approximations (Gaussian distributions and linearity), the asserted equivalence of simultaneous vs. sequential analysis is also approximate. To examine the validity of this equivalenoe, the artifioial data of example 2 were analyzed three 
TABLE VT.3. FARAMETER TALUES TOR EXAMPLE NUUBER ?

USING CONSTANT DATA COVARIANCE TO OFFSET IMPROPER BACKGROUND SUBTRACTION

\begin{tabular}{|c|c|c|c|c|c|}
\hline & $\begin{array}{l}\text { A. } \\
\text { Exact } \\
\text { Values }\end{array}$ & $\begin{array}{l}\quad \text { B. } \\
\text { Input } \\
\text { Values }\end{array}$ & $\begin{array}{l}\quad \text { C. } \\
\text { Results } \\
\text { from } \\
\text { MULTI }\end{array}$ & $\begin{array}{l}\text { D. } \\
\text { Results from } \\
\text { SAMMY wilh } \\
\text { no Correlations } \\
\text { in Data Set }\end{array}$ & $\begin{array}{l}\quad \bar{E} . \\
\text { Results from } \\
\text { SAMMY with } \\
\text { Additive Constant } \\
\text { Data Covariance }\end{array}$ \\
\hline$E_{r e s}(S)$ & $156.31 \mathrm{keV}$ & 156.50 & $156.29 \pm .01$ & $156.32 \pm .01$ & $156.3^{1} \pm .01$ \\
\hline$\Gamma_{n}(S)$ & $480.00 \mathrm{eV}$ & 500.00 & $730.18 \pm 10.72$ & $654.28 \pm 11.46$ & $486.85 \pm 9.75$ \\
\hline $\bar{E}_{r e s}(s)$ & $161.69 \mathrm{keV}$ & 162.00 & $161.62 \pm .01$ & $161.7^{1} \pm .01$ & $161.69 \pm .01$ \\
\hline$\Gamma_{n}(S)$ & $1330.0 \mathrm{eV}$ & 1300.0 & $1350.6 \pm 21.69$ & $1204.9 \pm 21.0$ & $1326.3+22.07$ \\
\hline$E_{\text {res }}(P)$ & $151.36 \mathrm{keV}$ & 151.40 & $151.21_{ \pm .01}$ & $151.41 \pm .01$ & $151.37 \pm .01$ \\
\hline$\Gamma_{n}(P)$ & $17.000 \mathrm{eV}$ & 18.000 & $59.908 \pm 2.094$ & $29.295 \pm 1.675$ & $18.229 \pm 1.801$ \\
\hline$E_{\text {res }}(P)$ & $154.30 \mathrm{keV}$ & 154.40 & $154.30 \pm .0$ & $154.3^{1} \pm .01$ & $154.30 \pm .01$ \\
\hline$\Gamma_{n}(P)$ & $166.00 \mathrm{eV}$ & 170.00 & $349.09 \pm 5.20$ & $310.67 \pm .5 .92$ & $170.77 \pm 4.95$ \\
\hline$E_{\text {res }}(P)$ & $160.16 \mathrm{keV}$ & 160.20 & $160.19 \pm .01$ & $160.21 \pm .01$ & $160.17 \pm .01$ \\
\hline$n_{n}(P)$ & $18.000 \mathrm{eV}$ & 17.500 & $65.117 \pm 1.504$ & $33.888 \pm 1.663$ & $17.272 \pm 1.516$ \\
\hline
\end{tabular}



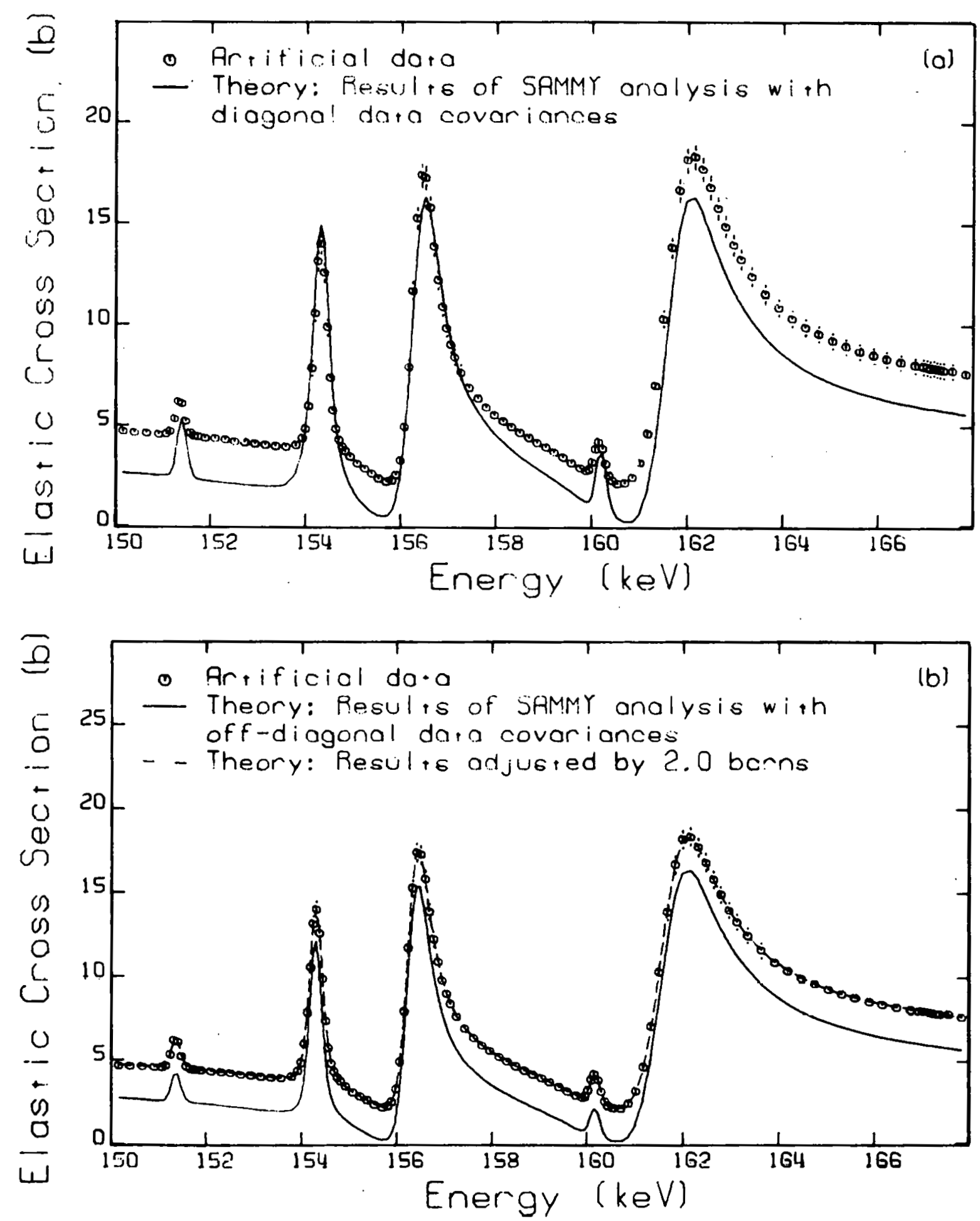

Fig. VI.3. Artificial. data used to study the effect of improperly subtracted background. The theoretical curve in part a shows the results of the SAMMY analysis with diagonal data covariance matrix, in part $b$ with off-diagonal covariance matrix. The dashed curve in part $b$ is the solid curve adjusted by 2.0 barns, which is the value of the unsubtracted background. 
different ways: First, all 123 data points were included simultaneously; results are given in Column $C$ of Table VI.4, part a. Secondly, a lowenergy piece (65 data points, from $150 \mathrm{keV}$ to $158 \mathrm{keV}$ ) was analyzed first, followed by the remajning data (58 data points, 158 to $168 \mathrm{keV}$ ); results are in Column $D$ of the table. Finally, the order of the two segments was reversed, and the analysis repeated; results are in Column E. In all cases, the resonance energjes were held fixed and neutron widths varied; only diagonal data covariances were included. Agreement among the three calculations is well within the quoted uncertainties.

In part $b$ of Table VI.4, the calculations are repeated with more accurate values as input. Again agreement among the three calculations is within the quoted uncertainties. (It js interesting to note that the output values are only weakly dependent on input values; this is to be expected when input uncertainties are large.) 
TABI.E VI.4. SIMULTANEOUS VS. SEQUENTIAL ANAL.YSIS OF AN S-WAVE RESONANCE FOR THO SETS OF STARTING VALUES

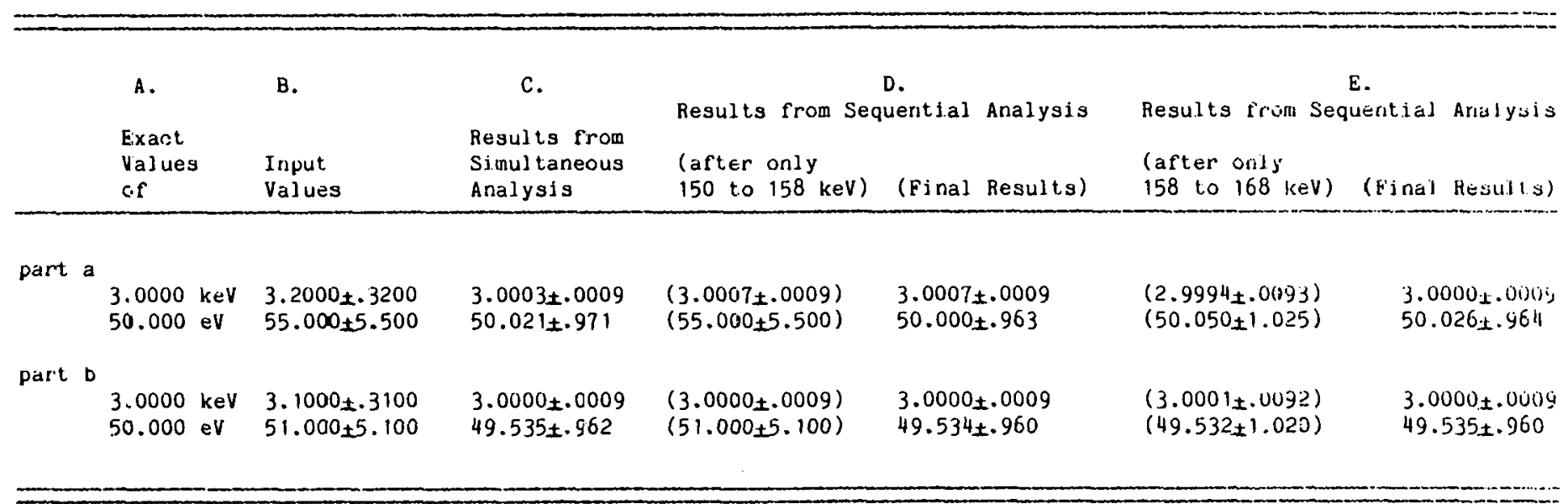




\section{THIS PAGE \\ WAS INTENTIONALLY \\ LEFT BLANK}


VII. SUMMARY AND CONCLUSTONS

This report is intended as a users' guide to the Bayesian multilevel R-matrix code SAMMY. Bayes' theorem and our reasons for preferring its use to the customary least-squares approach are discussed in some detail, as are the assumptions required for the derivation of Bayes' equations from Bayes' theorem. A summary of multilevel R-matrix theory, as implemented in SAMMY, is presented. Four examples of data analyses are presented, illustrating both the strengths of Bayes' method and the necessity of including data correlations (off-diagonal data covariances). Thus in this report, we have attempted not only to explain how to use SAMMY, but also to indicate some of its advantages over MULT, a code incorporating the same R-matrix theory formulations but using conventional least squares.

The code SAMMY is available from the Radiation Shielding Information Center (RA80). The authors would appreciate any comments on all aspects of SAMMY, including suggestions for refinements. 


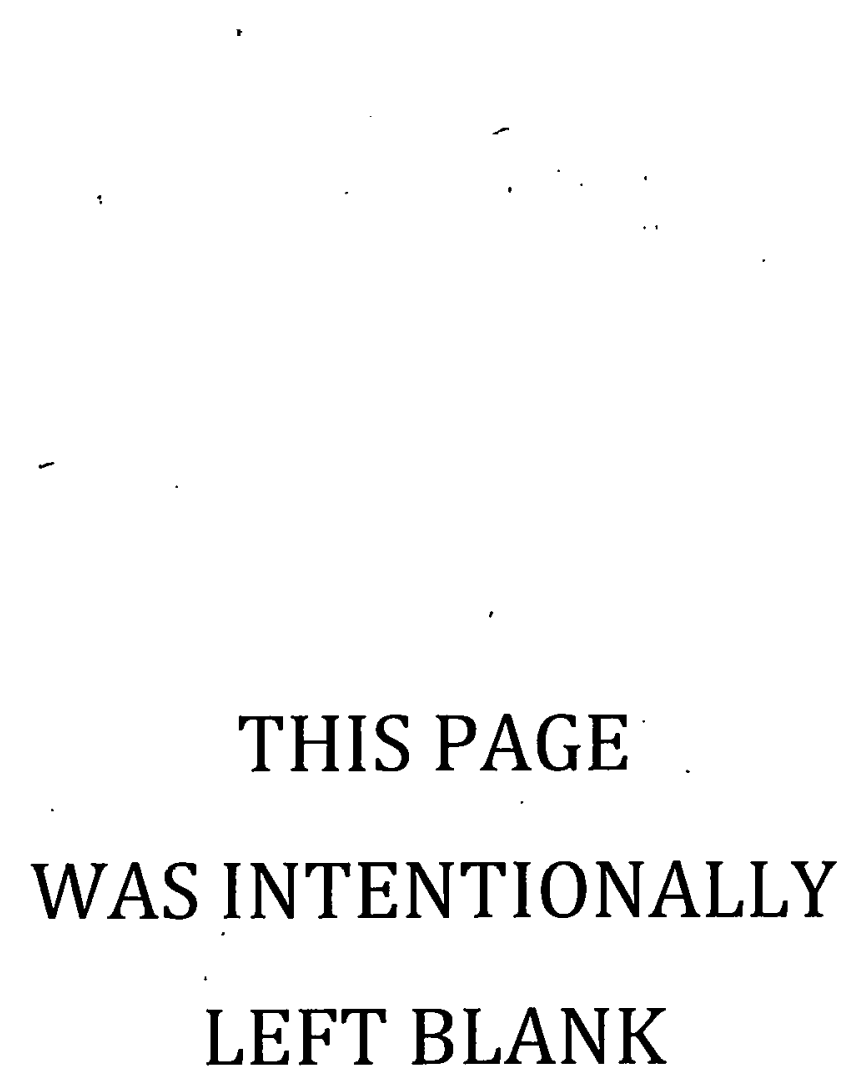


AU74 George F. Auchampaugh, MULII, A EORTRAN Cede fer Least-Squares Shape Eitting of Neutron Cross-Section Data Lsing the Reich-Meere MultiLeved Formalism, LA-5473-MS, Los Alamos Scientific Laboratory, Los Alamos, NM (1974).

CR78 J. G. Craven, ØPRøDE_ A DECsystem-10 Data_Manidudation__rogram_fer eRELA Data Formatted_Eiles, ORNL/CSD/TM-45 (May 1978).

DE78 G. deSaussure, D. K. Olsen, R. B. Perez, SIØBi.A.EØRTRAN Cede Cer Least-Squares Shape Fitting Severad Neutren Transmission Measucements Lsing the Brejt-Wigner Mult ideved Formula, ORNL/TM-6286, ENDF-261

D079 J. J. Dongarra, C. B. Moler, J. R. Bunch, G. W. Stewart, LINRACK Usecs' Gujde, SIAM (1979).

FR80 F. H. Froehner, "Applied Neutron Resonance Theory", reprinted from Nuclear Theory for Apelications, p. $59 \mathrm{ff}$., International Centre for Theoretical Physics, Trieste (1980). Available as KFK 2889 (1978).

HA80 J, A. Harvey, private communication.

LA58 A. M. Lane and R. G. Thomas, Rekemedembyse 30, p. 257 (1958).

LA80 N. M. Larson, to be published.

PE79 F. G. Perey, lecture notes "Introduction to Probability Theory and Applications to Neutron and Reactor Physics Problems", unpublished.

PE80a F. G. Perey, to be published.

PE80b R. W. Peelle, "Uncertainty in the Nuclear Data Used for Reactor Calculations", in "Procedures for Evaluating Uncertainties in Estimated Reactor Performance Parameters", to be published in AdyeNucdescienand Technelegy, Plenum Press, editor Martin Becker.

PE80c C. Perey, private communication.

RA80 Radiation Shielding Information Center, Oak Ridge National Laboratory, P. D. Box X, Dak Ridge, TN 37830 .

RE58 C. W. Reich and M. S. Moore, Bhysereyen11, p. 929 (1958). (1978). 
52

\section{THIS PAGE}

WAS INTENTIONALLY

\section{LEFT BLANK}


APPENDIX A. ALGEBRAIC DETAILS

In this appendix are presented those algebraic details which, though jmportant for complete understanding of the theory manifested in SAMMY, are sufficiently complex so as to obscure the broad understanding of our method were they to be presented in the text. Included here are the derivation of Bayes' equations from Bayes' theorem, development of an appropriate iteration scheme for Bayes' theorem, a derivation of least-squares equations from Bayes' equations, a proof that a constant covariance matrix is equivalent to a coherent data correction, and evaluation of the derivatives of $x^{-1}$

\section{Deriving Bayes' Equations}

In Section II, a detailed discussion of Bayes' theorem and its application to neutron physics is presented. It is stated there that Bayes' equations may be derived directly from Bayes' theorem,

$$
p(A \mid B X) \propto p(A \mid X) p(B \mid A X)
$$

provided the three basic assumptions are met. These assumptions are:

i) the prior pdf is a joint normal. That is, the pdf for the parameters, prior to consideration of the data $B$, is

$$
\dot{p}(A \mid X) \propto \exp \left\{-\frac{1}{2}(P-\bar{P})^{t} M^{-1}(P-\bar{P})\right\}
$$

ii) the likelihood function is a joint normal. That is, the pdf for the experimental data is

$$
p(B \mid A X) \propto \exp \left\{-\frac{1}{2}(D-T)^{t} V^{-1}(D-T)\right\}
$$


iii) the true value is a linear function of the parameters. That is, a Taylor expansion of the theoretical values around the prior expectation values of the parameters truncates after the linear term:

$$
T=\bar{T}+G(P-\bar{P})
$$

where the sensitivity matrix $G$ is defined by

$$
\mathrm{G}_{\mathrm{k}}^{\mathrm{i}}=\left.\frac{\partial \mathrm{T}^{\mathrm{i}}}{\partial \mathrm{P}_{\mathrm{k}}}\right|_{\mathrm{P}=\overline{\mathrm{P}}}
$$

and the theoretical value $\overline{\mathrm{T}}^{i}$ is also evaluated at $\mathrm{P}=\overline{\mathrm{P}}$.

Given these three assumptions, the posterior $\operatorname{pdf} p(A \mid B X)$ is also a joint normal distribution and may be written

$$
P(A \mid B X) \propto \exp \left\{-\frac{1}{2}\left(P-\bar{P}^{\prime}\right)^{t}\left(M^{\prime}\right)^{-1}\left(P-\bar{P}^{\prime}\right)\right\} .
$$

Substitution of $\mathrm{Eq}$. (A2) through (A6) into Eq. (A1) and equating the exponents yields, in matrix form,

$$
\begin{aligned}
&\left(P-\bar{P}^{\prime}\right)^{t}\left(M^{\prime}\right)^{-1}\left(P-\bar{P}^{\prime}\right)+Y=(P-\bar{P})^{t} M^{-1}(P-\overline{\bar{P}}) \\
&,[D-\bar{T}-C(P-\bar{P})]^{t} V^{-1}[D-\bar{T}-G(P-\bar{P})]
\end{aligned}
$$

where $Y$ represents the normalization constant and is independent of $P$. 
Setting $P-\bar{P}=P-\bar{P}^{\prime}+\bar{P}^{\prime}-\bar{P}$ in Eq. (A7), and rearranging terms, we obtain

$$
\begin{aligned}
\left(P-\bar{P}^{\prime}\right)^{t}\left(M^{\prime}\right)^{-1}\left(P-\bar{P}^{\prime}\right)+Y & =\left(P-\bar{P}^{\prime}\right)^{t}\left(M^{-1}+G^{t} V^{-1} G\right)\left(P-\bar{P}^{\prime}\right) \\
& +\left(P-\bar{P}^{\prime}\right)^{t}\left[\left(M^{-1}+G^{t} V^{-1} G\right)\left(\bar{P}^{\prime}-\bar{P}\right)-G^{t} V^{-1}(D-\bar{T})\right] \\
& +\left[\left(\bar{P}^{\prime}-\bar{P}\right)^{t}\left(M^{-1}+G^{t} V^{-1} G\right)-(D-\bar{T})^{t} V^{-1} G\right]\left(P^{\prime}-\bar{P}^{\prime}\right) \\
& +\left(\bar{P}{ }^{\prime}-\bar{P}\right)^{t} M^{-1}\left(\bar{P}^{\prime}-\bar{P}\right) . \\
& +\left[D-\bar{T}-G\left(\bar{P}^{\prime}-\bar{P}\right)\right]^{t} V^{-1}\left[D-\bar{T}-G\left(\bar{P}^{\prime}-\bar{P}\right)\right]
\end{aligned}
$$

Because Eq. (A8) must hold for all values of $P$, we may equate terms quadratic, linear, or constant in $\left(P-\bar{P}^{\prime}\right)$. Equating the quadratic terms gives Bayes' equation for updating the covariance matrix:

$$
\left(M^{\prime}\right)^{-1}=M^{-1}+G^{t} V^{-1} G
$$

Multiplication of both sides by $M$ on the left and $M^{\prime}$ on the right yields

$$
M^{\prime}=\left[1+M G^{t} V^{-1} G\right]^{-1} M
$$

Using the identity $X^{-1}=(Y X)^{-1} Y$ with $Y=G^{t}(N+V)^{-1} G$, substituting $\mathrm{N}$ for $\mathrm{GMG}^{t}$, and rearranging give

$$
M^{\prime}=\left[G^{t}\left\{(N+V)^{-1}\left(1+N V^{-1}\right)\right\} G\right]^{-1} G^{t}(N+V)^{-1} G M
$$

The quantity in curly brackets in $\mathrm{Eq} .\left(\mathrm{A} 11\right.$ ) is equal to $\mathrm{V}^{-1}$; introducing the identity $\mathrm{V}^{-1} \mathrm{~V}=\mathrm{I}$ into that equation gives

$$
M^{\prime}=\left[G^{t} V^{-1} G\right]^{-1} G^{t} V^{=1} V(N+V)^{-1} G M
$$


Algebraic manipulation then yields

$$
M^{\prime}=\left[G^{t} V^{-1} G\right]^{-1} G^{t} V^{-1} G M-\left[G^{t} V^{-1} G\right]^{-1} G^{t} V^{-1} G M G(N+V)^{-1} G M
$$

which reduces to

$$
M^{\prime}=M-M G^{t}(N+V)^{-1} G M \quad .
$$

This is exactly Bayes' equation for updating the covariance matrix, Eq. (II.II) or (III.2). Explicitly, this equation may be written

$$
M_{k \ell}^{\prime}=M_{k \ell}-\sum_{n=1}^{K} \sum_{i=1}^{L} \sum_{j=1}^{L} \sum_{n=1}^{K} M_{k n} G_{n}^{i}\left((N+V)^{-1}\right)^{i j G_{m}^{j}{ }_{m}{ }_{m \ell}}
$$

where $\mathrm{N}$ is given by

$$
\mathrm{N}^{\mathrm{ij}}=\sum_{\mathrm{k}=1}^{\mathrm{K}} \sum_{\ell=1}^{\mathrm{K}} \mathrm{G}^{\mathrm{i}} \mathrm{k}_{\mathrm{k} \ell} \mathrm{G}_{\ell}{ }^{\mathrm{j}}
$$

To obtain Bayes' equation for updating the parameter values, we equate the linear terms of $\mathrm{Eq}$. (A8). Since the left-hand side of that equation has no terms linear in $\left(P-\bar{P}^{\prime}\right)$, the coef'ficient of $\left(P-P^{\prime}\right)$ on the right-hand side must be zero. That is,

$$
\left(M^{-1}+G^{t} V^{-1}(\dot{G})\left(\bar{Y}^{\top}-\bar{P}\right)=G^{+} V^{-1}\left(D-T^{\prime}\right)\right.
$$

From Eq. (A9), the first quantity on the left is just (M') ${ }^{-1}$; we therefore multiply both sides of Eq. (Ai.7) by M', using Eq. (Al4), and obtain

$$
\overline{\mathrm{P}}^{\prime}-\overline{\mathrm{P}}=\left(\mathrm{M}-\mathrm{MG}{ }^{\mathrm{t}}(\mathrm{N}+\mathrm{V})^{-1} \mathrm{GM}\right) \mathrm{G}^{\mathrm{t}} \mathrm{V}^{-1}(\mathrm{D}-\overline{\mathrm{T}})
$$

which reduces to

$$
\overline{\mathrm{P}}^{\prime}-\overline{\mathrm{P}}=\mathrm{MG}^{\mathrm{t}}(\mathrm{N}+\mathrm{V})^{-1}(\mathrm{D}-\overline{\mathrm{T}})
$$


Explicitly, this equation is

$$
\overline{\mathrm{P}}_{\mathrm{k}}^{\prime}=\overline{\mathrm{P}}_{\mathrm{k}}+\sum_{\ell=1}^{\mathrm{K}} \sum_{i=1}^{\mathrm{L}} \sum_{j=1}^{\mathrm{L}} \mathrm{M}_{\mathrm{k} \ell} \mathrm{G}_{\ell}^{i}\left((\mathrm{~N}+\mathrm{V})^{-1}\right)^{\mathrm{i} j}\left(\mathrm{D}^{\left.\mathrm{j}-\overline{\mathrm{T}}^{\mathrm{j}}\right)}\right.
$$

Finally, we note that the constant term in Eq. (A8) may be simplified using $\mathrm{Eq} .(\mathrm{A} 19)$ to give

$$
Y=(D-\bar{T})^{t}\left[(N+V)^{-1}{ }_{G M G}^{t}(N+V)^{-1}+\left(1-(N+V)^{-1} N\right) V^{-1}\left(1-N(N+V)^{-1}\right)\right](D-\bar{T})
$$

which reduces to

$$
\mathrm{Y}=(\mathrm{D}-\overline{\mathrm{T}})^{t}(\mathrm{~N}+\mathrm{V})^{-1}(\mathrm{D}-\overline{\mathrm{T}})
$$

\section{Iteration Scheme}

The linearity hypothesis, i.e., the assumption that the Taylor expansion of the theoretical values around the prior expectation value truncates after the linear term, is in fact only approximately true. Therefore, the parameter values $\bar{P}^{\prime}$ resulting from application of Bayes' equations are also only approximately correct. To obtain more accurate values, the Taylor expansion, Eq. (A4), may be performed not around $\bar{P}$ but around the new (intermediate) values $\overline{\mathrm{P}}^{(n)}$, where $\mathrm{n}$ represents the $n$th iteration and $\overline{\mathrm{p}}^{(0)} \equiv \overline{\mathrm{P}}$ :

$$
T \simeq \bar{T}^{(n)}+G^{(n)}\left(P-\bar{P}^{(n)}\right) .
$$


Here the sensitivity matrix $G^{(n)}$ and the theoretical values $\bar{T}^{(n)}$ are evaluated at $P=\bar{P}^{(n)}$. With Eq. (A23) for $T$, the formula analogous to Eq. (A7) is

$$
\begin{aligned}
& \left(P-\bar{P}^{(n+1)}\right)^{t}\left(M^{(n+1)}\right)^{-1}\left(P-\bar{P}^{(n+1)}\right)+Y=(P-\bar{P})^{t} M(P-\bar{P}) \\
& +\left[D-\bar{T}^{(n)}-G^{(n)}\left(P-\bar{P}^{(n)}\right)\right]^{t} V^{-1}\left[D-\bar{T}^{(n)}{ }_{-G}^{(n)}\left(P-\bar{P}^{(n)}\right)\right] .
\end{aligned}
$$

Setting $P$ equal to $P-\bar{P}^{(n+1)}+\bar{P}^{(n+1)}$ everywhere in the right-hand side of $\mathrm{Eq}$. (A24) gives the formula analogous to $\mathrm{Eq}$. (A8), with $\overline{\mathrm{T}}$ in that expression replaced by $\bar{T}^{(n)}-G^{(n)}\left(\bar{P}-\bar{P}^{(n)}\right)$, and $G$ by $G^{(n)}$. The iterative Bayes' equations follow immediately:

$$
\begin{aligned}
& \overline{\mathrm{P}}^{(\mathrm{n}+\mathrm{l})}=\overline{\mathrm{P}}+\mathrm{MG}^{(\mathrm{n}) t}\left(\mathrm{~N}^{(\mathrm{n})}+\mathrm{V}\right)^{-1}\left(\mathrm{D}-\overline{\mathrm{T}}^{(\mathrm{n})}-\mathrm{G}^{(\mathrm{n})}\left(\overline{\mathrm{P}}-\overline{\mathrm{P}}^{(\mathrm{n})}\right)\right) \\
& M^{(n+1)}=M-M G^{(n) t}\left(N^{(n)}+V\right)^{-1} G^{(n)} M
\end{aligned}
$$

where

$$
N^{(n)}=G_{M G}^{(n)}{ }^{(n) t} .
$$

\section{Derivation of Least Squares from Bayes' Equations}

The equivalence of the least-squares method with Bayes' equations in the limit of large M (i,e., in the extreme case where there is no prior knowledge of the values of the parameters) is best demonstrated by considering Eq. (AI7):

$$
\left(M^{-1}+G^{t} V^{-1} G\right)\left(\bar{P}^{\prime}-\bar{P}\right)=G^{t} V^{-1}(D-\bar{T})
$$


or, in the iterative form,

$$
\begin{aligned}
\left(M^{-1}+G^{(n) t} V^{-1} G^{(n)}\right)\left(\bar{P}^{(n+1)}-\bar{P}\right) \\
\quad=G^{(n) t} V^{-1}\left(D-\bar{T}^{(n)}-G^{(n)}\left(\bar{P}-\bar{P}^{(n)}\right)\right) .
\end{aligned}
$$

For large $M$, the term $G^{t} V^{-1} G$ overwhelms $M^{-1}$, and this equation reduces immediately to

$$
\overline{\mathrm{P}}^{(n+1)}=\overline{\mathrm{P}}^{(\mathrm{n})}+\left(G^{(n) t} \mathrm{~V}^{-1} G^{(n)}\right)-1 G^{(n) t} V^{-1}\left(D-\bar{T}^{(n)}\right)
$$

which is the well-known least-squares formula.

Similarly, parameter uncertainties and covariances can be found from the iterative form of $\mathrm{Eq}$. (A9):

$$
\left(M^{(n+1)}\right)^{-1}=M^{-1}+G^{(n)} t_{V}^{-1} G^{(n)}
$$

which reduces to

$$
1^{(n+1)}=\left(G^{(n) t_{V}-1}{ }_{G}^{(n)}\right)^{-1}
$$

in the limit of large $M$. In least-squares applications, the quoted covariance matrix is usually the value given in Eq. (A32), multiplied by $x^{2}$, where

$$
x^{2}=\frac{1}{d}\left(D-\bar{T}^{(n) t}\right) V^{-1}\left(D-\bar{T}^{(n)}\right)
$$

$d$ being the number of degrees of freedom in the problem ( $d=$ number of data points minus number of parameters). 
4. Use of Data Covariances to Indicate Coherent Data Corrections

In Section III.3, we indicated that a constant term added to the data covariance matrix is mathematically equivalent to a constant, coherent correction to either the data or the theory. To see that this is so, write the covariance matrix in the form

$$
V=\bar{V}+A^{t}
$$

where $\bar{V}$ is the original covariance matrix, and $A$ is a column matrix whose elements are zero outside the range where the correction is to be applied, and constant inside the range. Bayes' equations require the inverse of $\mathrm{N}+\overline{\mathrm{V}}+\mathrm{AA}{ }^{\mathrm{t}}$, which is equivalent to

$$
\left(N+\bar{V}+A^{t}\right)^{-1}=(N+\bar{V})^{-1}\left[1-\frac{1}{1+A^{t}(N+\bar{V})^{-1} A} A^{t}(N+\bar{V})^{-1}\right]
$$

as can be verified by multiplying the right-hand side by $\left(N+\bar{V}+A A^{t}\right)$. Substitution of this expression into the first of Bayes' equations ( $E q$. III.1) gives

$$
\overline{\mathrm{P}}^{\prime}=\overline{\mathrm{P}}+\mathrm{MG}(\mathrm{N}+\overline{\mathrm{V}})^{-1}(\mathrm{D}-\Delta \mathrm{D}-\overline{\mathrm{T}})
$$

where the correction term $D$ is given by

$$
\Delta D=\frac{1}{1+A^{t}(N+\bar{V})^{-1} A} A A^{t}(N+\bar{V})^{-1}(D-\bar{T})
$$

Thus, the presence of an additive constant term ( $\mathrm{AA}^{\mathrm{t}}$ ) in the data covariance matrix is equivalent to a coherent correction to the data or to the theory. Also, note that if the elements of column matrix A are not zero or constant, Eqs. (A36) and (A37) remain valid, but the correction term $\Delta D$ varies from point to point. 
5. Derivative of $X^{-1}$ with Respect to $R$

In Section $V$, we require the derivative of $Y=X^{-1}$ with respect to $R$, where the matrix $X$ is given by

$$
\mathrm{X}_{\mu \nu}=\frac{\delta_{\mu \nu}}{\mathrm{L}_{\mu}}-\mathrm{R}_{\mu \nu}
$$

To determine the derivative of $Y$ with respect to $X$, note that the derivative of

$$
\sum_{\beta} \mathrm{X}_{\varepsilon \beta} \mathrm{Y}_{\beta \alpha}=\delta_{\varepsilon \alpha}
$$

with respect to $x_{\mu \nu}$ is

$$
\sum_{\beta}\left[\delta_{\varepsilon \mu} \delta_{\beta \nu}+\delta_{\varepsilon \nu} \delta_{\beta \mu}\left(1-\delta_{\mu \nu}\right)\right] Y_{B \alpha}+\sum_{\beta} X_{\varepsilon \beta} \frac{\partial Y_{B \alpha}}{\partial X_{\mu \nu}}=0
$$

Multiplication by $\mathrm{Y}_{\omega \varepsilon}$ and summation over $\varepsilon$ give

$$
Y_{\omega \mu} Y_{\nu \alpha}+Y_{\omega \nu} Y_{\mu \alpha}\left(1-\delta_{\mu \nu}\right)+\frac{\partial Y_{\omega \alpha}}{\partial X_{\mu \nu}}=0
$$

where we have used the fact that $Y$ is the inverse of $X$. Finally, we note that the derivative with respect to $R$ is the negative of the derivative with respect to $X$; this gives

$$
\frac{\partial Y_{\omega \alpha}}{\partial R_{\mu \nu}}=Y_{\omega \mu} Y_{\nu u}+Y_{\omega \nu} Y_{\mu \alpha}\left(1-\delta_{\mu \nu}\right)
$$

for the required derivative $(\mathrm{Eq},(\mathrm{V}, 12)$ in the text). 
62

THIS PAGE

WAS INTENTIONALLY

LEFT BLANK 
APPENDIX B. DESCRIPTION OF THE COMPUTER CODE SAMMY

The computer code SAMMY was developed for ease and efficiency of rurning on the DECsystem-10 (PDP-10) at ORELA. (Conversion to other machines should nevertheless be straightforward; helpful suggestions are given at the end of this appendix.) Because core storage rather than CPU time is the limiting factor on the PDP-10, a number of techniques have been used to preserve core, occasionally at the experse of runtime. These techniques include dynamic allocation of array storage, use of temporary data files to store intermediate results, and division of the program into four substationally independerit segments.

\section{Dyramic Allocation of Array Storage}

Al]. arrays required by the computer program are stored in one location in CØMMøN/EXPAND/A( $n)$ where $n$ is a large number. Allocation of space in this common block is accomplished via a call to FUNCTIØN IDIMEN, which remembers the last location allocated, and appends the new array to that position. When an array is no longer needed, its space is released for future use via another cal. I to IDIMEN. IDIMEN issues a warning if more than $\mathrm{n}$ words are required in CØMMØN/EXPAND/, and al so indicates the maximum size actually used in each segmert of the program.

Dyramic allocation of array storage is best illustrated with a simple example. Let us suppose that two vectors $V 1$ and $V 2$, both of length $N$, are to be initialized, added, and stored in $V 1$, after which $V 2$ is no longer required. A program to perform these operations is given in Table B.1. Notice that mremonic names can be used in the usual manner in all subroutines, provided arrays are input to the subroutines through argument listings. 
TABLE B. 1. ILLUSTRATION OF DYNAMIC ALLOCATION OF ARRAY STORAGE

PRØGRAM MAIN

CØMMØN/EXPAND/A (10000)

CØMMøN/ØVER/NSIZE

NSIZE $=10000$

$\dot{N}=50$

$1 V 1=\operatorname{IDIMEN}(\mathrm{N})$

IV2 $=\operatorname{IDIMEN}(\mathrm{N})$

CALL $\cdot \operatorname{SET}(A(I V 1), A(I V 2), N)$

CALL $A D D(A(I V 1), A(I V 2), N)$

I = IDIMEN $(-$ IV2 $)$

$T=\operatorname{IDIMEN}(0)$

STøP

END

SUBRøUTINE SET $(\mathrm{V} 1, \mathrm{~V} 2, \mathrm{~N})$

DIMENST, ØN $\mathrm{V} 1(\mathrm{~N}), \mathrm{V} P(\mathrm{~N})$

READ (II) VI

RF.AN (11) V?

RETURN

END allocate storage for V1

allocate storage for V2

initialize $\mathrm{V} 1$ and $\mathrm{V} 2$

add $\mathrm{V} 1=\mathrm{V} 1+\mathrm{V} 2$

release storage for $\mathrm{V} 2$

request that IDIMEN print out the maximum length used

SUBRøUTINE ADD $(\mathrm{V} 1, \mathrm{~V} 2, \mathrm{~N})$ DIMENSIØN $\mathrm{V} 1(\mathrm{~N}), \mathrm{V} 2(\mathrm{~N})$

Dø $10 \quad I=1, N$

$10 \mathrm{~V} 1(I)=\mathrm{V} 1(\mathrm{I})+\mathrm{V} 2(\mathrm{I})$ RETURN

END 
There are several advantages to using dyramic allocation of array storage: First, core requirements are kept to a minimum, since only the array length actually needed is allocated and temporary arrays are released when no longer needed. Secondly, because allocation is made during the execution of a program, substantial changes in the dimensions for a specific case do not always require recompilation of the program. Finally, when recompilation is required (when the maximum array space requirement is larger than $n)$, only the main routine need be recompiled; other routines using CØMMØN/EXPAND/A(1) will have array A dimensioned 1, since the loader allocates CøMMøN storage space according to the first subroutine loaded.

\section{Use of Temporary Data Files to Store. Intermediate Results}

Output to and input from temporary files is a time-honored method of saving core space at the expense of runtime. Temporary files gerierated by SAMMY are listed in Table B.2. Upon successful completion of a run, SAMMY deletes these files. An aborted run can sometimes be restarted if the user takes care not to destroy these files.

\section{Division of the Program into Four Stand-Alone Segments}

The structure of program SAMMY makes it ideally suited for overlay, since each major operation is independent of the others. However, overlay is not particularly efficient on the PDP-10 computer; instead, SAMMY makes use of the DECsystem-10 "CALL RUN" option, which allows a FøRTRAN program to initiate execution of another program. Thus SAMMY consists of four semi-autonomous programs, which pass information to each other via temporary files and which pass control to each other via the "CALL RUN" statement. Table B.3 describes the functions of the four segments. Tree charts showing the subroutine structure of each segment are given in Figs, B.1-B.4. 
TABLE B.2. TEMPORARY FILES USED BY SAMMY

\begin{tabular}{ll} 
File Name & Use \\
\hline SAM42.DAT & store covariance matrix for physical parameters \\
SAM43.DAT & store data and covariance matrix for the data \\
SAM44.DAT & store data and modified covariance matrix \\
SAM46.DAT & store eovaliance matrix for u-palameters \\
SAM47.DAT & store covariance matrix for updated u-parameters \\
SAM48.DAT & store partial derivatives \\
SAM49.DAT & pass minimal information from THEORY segment to \\
RESULT segment & $\begin{array}{l}\text { pass complete information between any two program } \\
\text { segments }\end{array}$
\end{tabular}


TABLE B.3. SEGMENTS OF THE CODE SAMMY

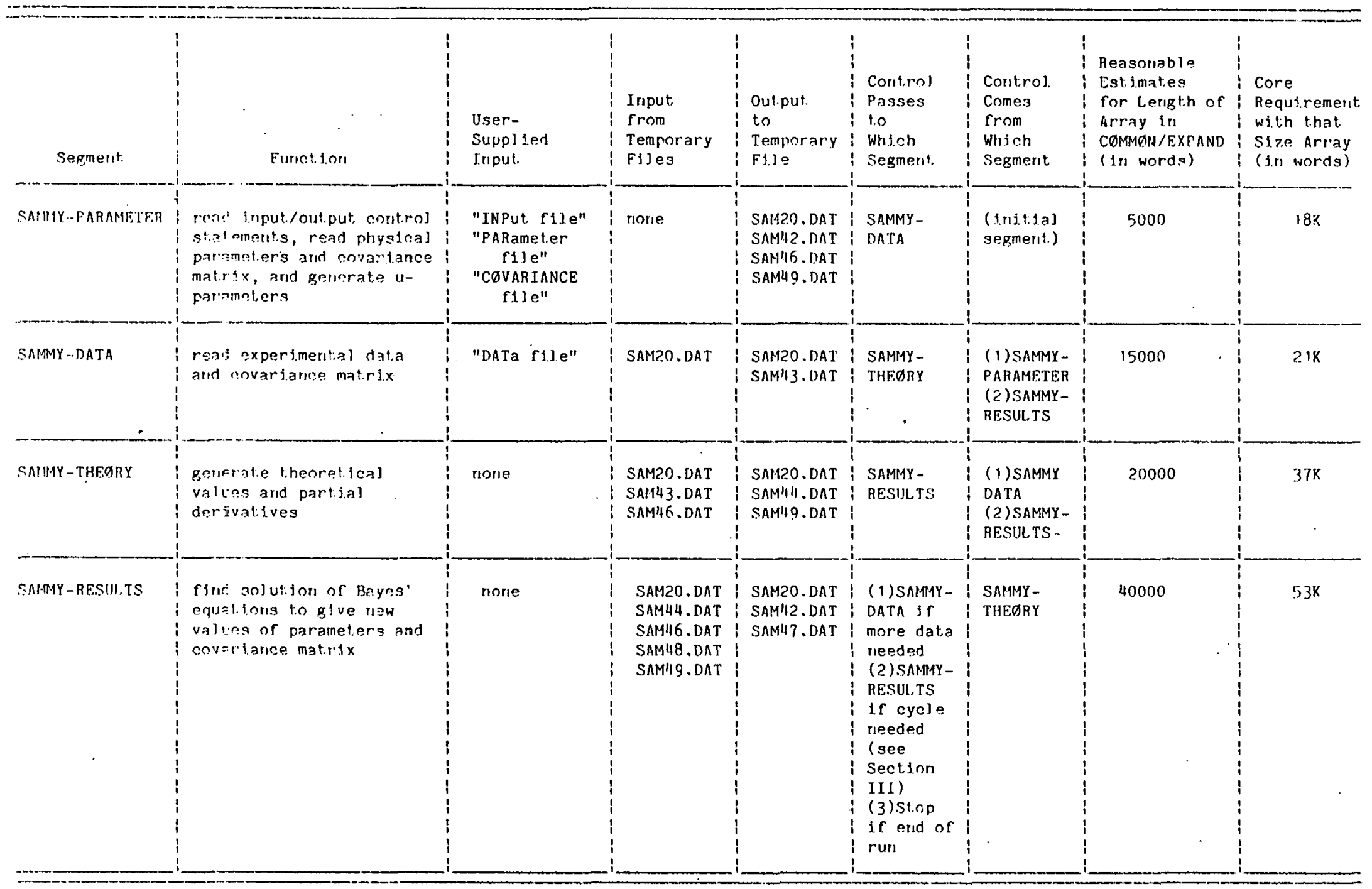




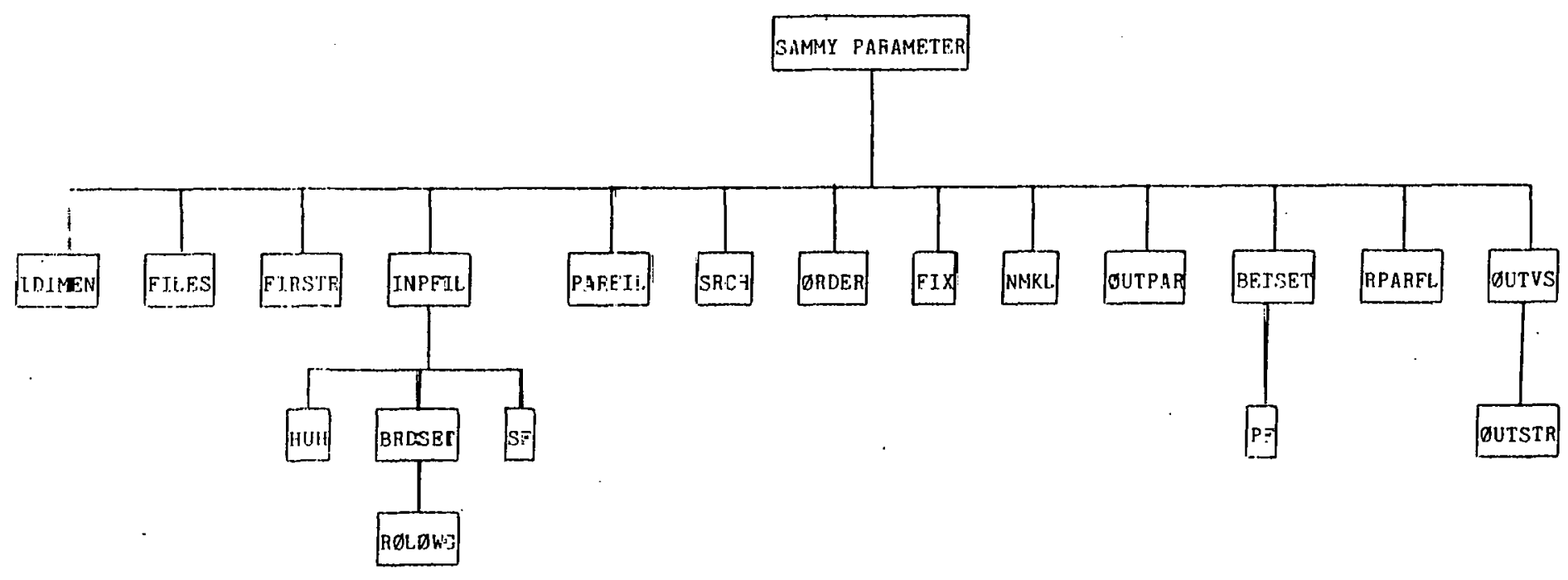

Fl.gune B. - Tree chart:s s owirug the subrout.:ne 3t.ructure of segment SAMMY-PARAME'TER. A subroutilie 1.s called by the rout. ine above 1.t in the char:. 


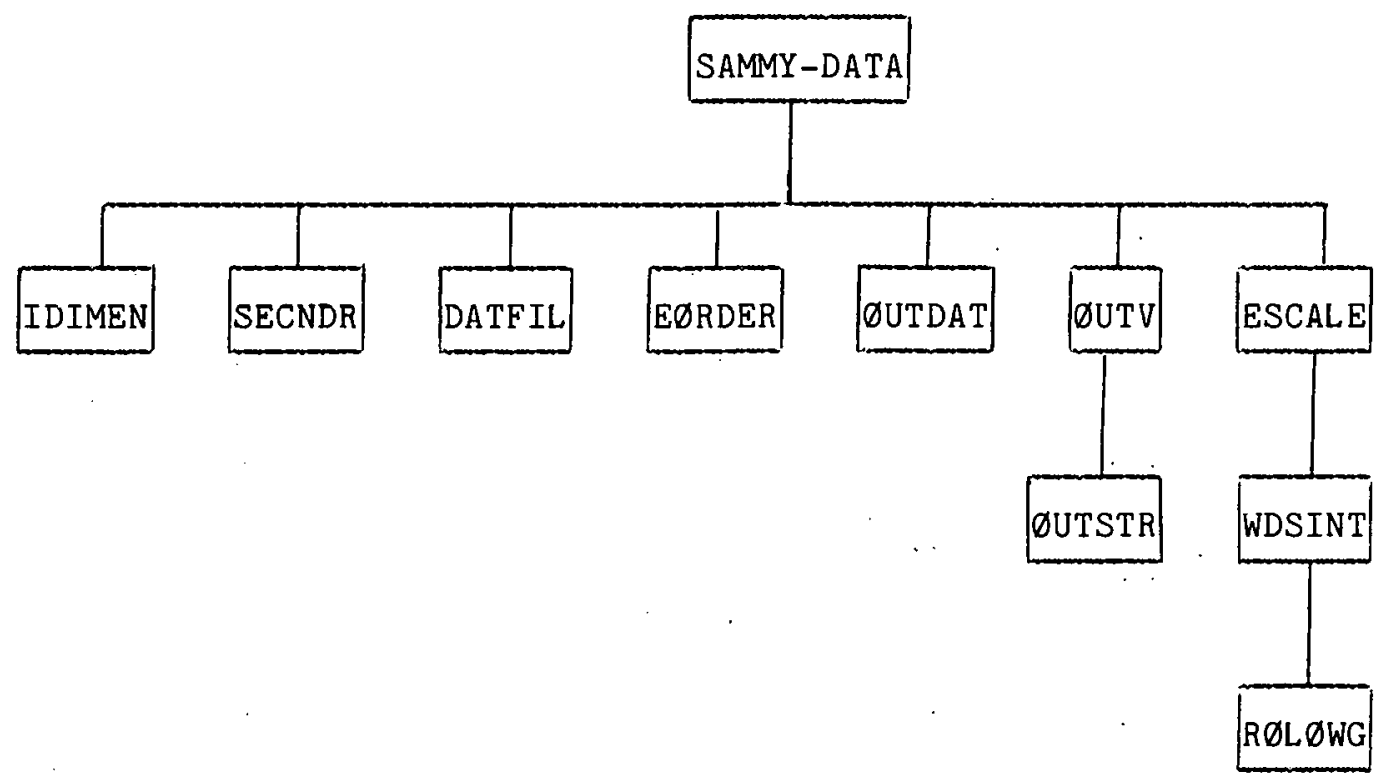

Figure B.2. Tree charts showing the subroutine structure of segment SAMMY-DATA. A subroutine is called by the routine above it in the chart. 


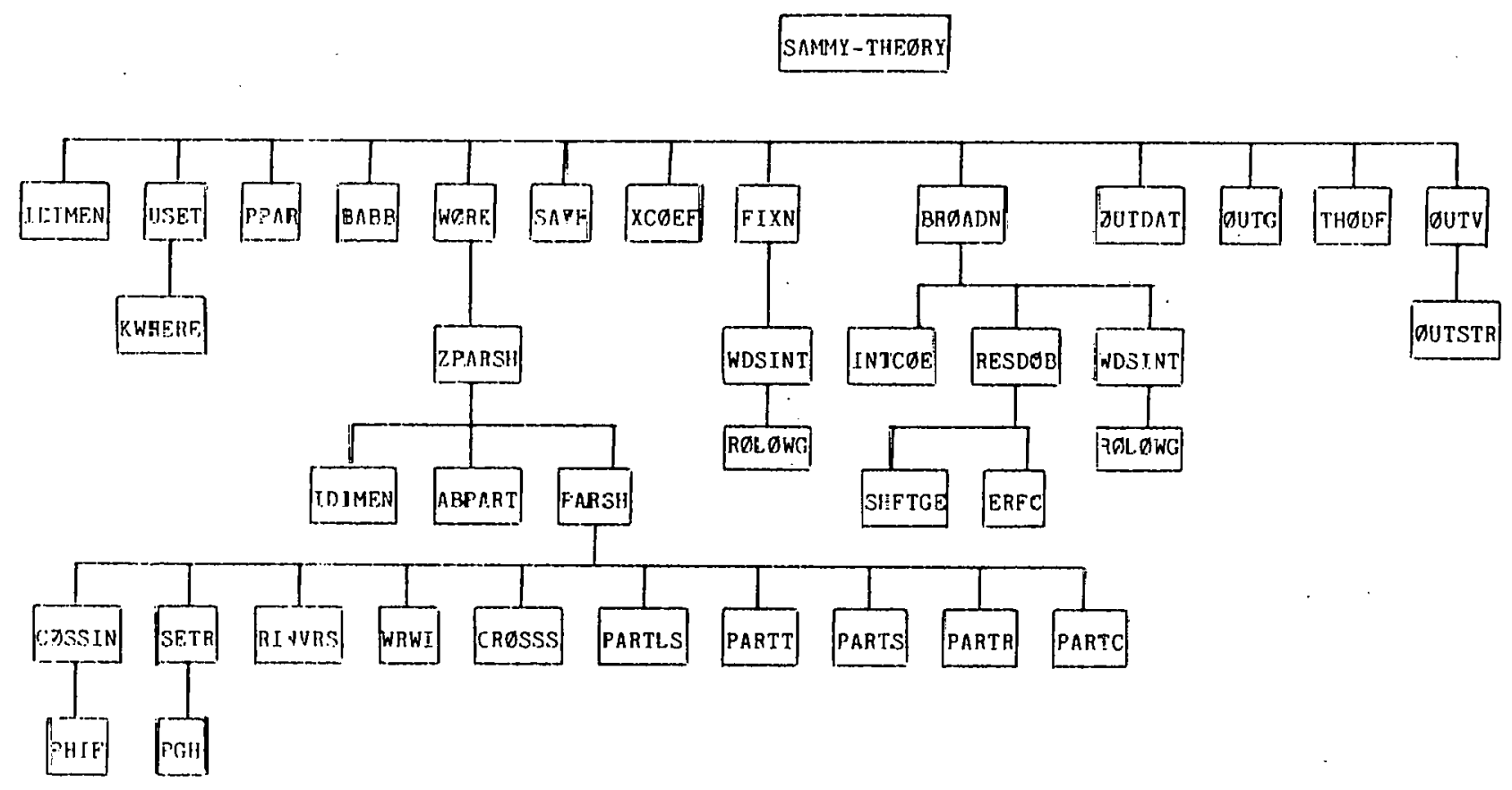

F4 hure B.:. Tree Charts showing the sube sutine szructure of segment. SAMMy-THEdRY. A subroutine 1s called by the routine above it in the chart. 
SAMMY - RESULTS

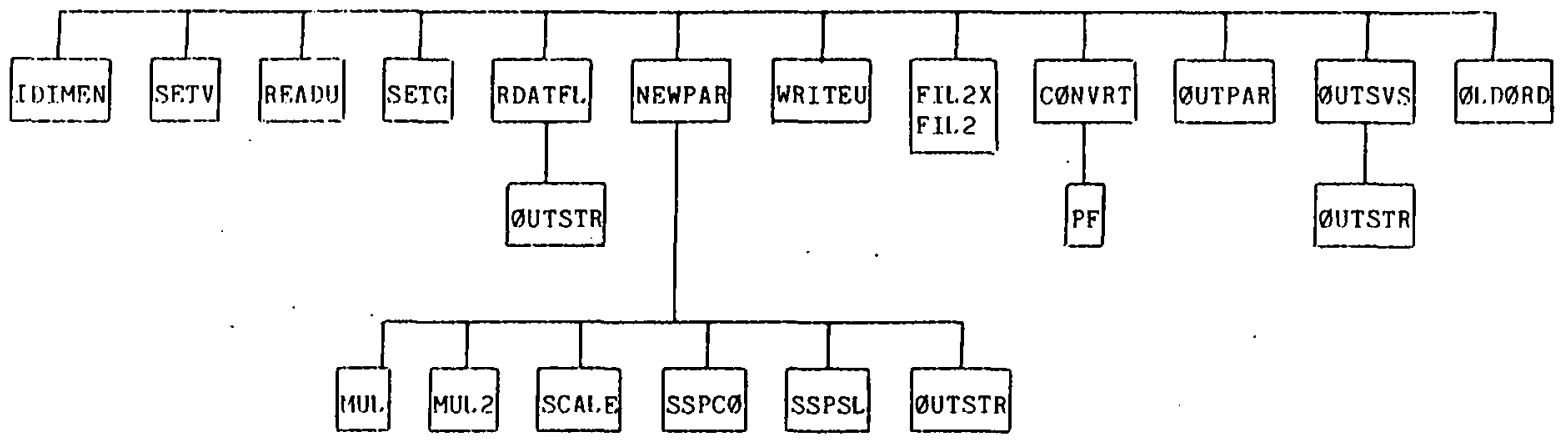

Fjgure B.4. Tree charts showing the subroutine structure of segment SAMMY-RESILTS. A subrout.Ine i.s called by the roult. ne above 1t. In the chart. 
4. Conversion to Other Computer Systems

Most of the programming iri SAMMY is standard FØRTRAN IV, with relatively few operations specific to the PDP-10 for which SAMMY was designed. For this reason, conversion to another computer should proceed without major difficulties.

No plotting options are available within SAMMY. Instead, an ØDF (QRELA Data Eormat) file may be generated, from which plots are produced using the in-house data-maripulating and plotting package ØPRøDF (CR78). Persons converting SAMMY to other systems should simply drop all references to $\emptyset \mathrm{DF}$ files, including subroutine THøDF in segment SAMMY-THEøRY, and the auxiliary program SAMØDF. Plotting routines suitable for the particular computer system can then be substituted.

File naming, opening, closing, deleting, and renaming are all done with FØRTRAN statements in SAMMY on the PDP-10 computer. Other computers máy requiré JCL (job control language) to accomplish these f'unctions.

Some computer systems may not allow one FØRTRAN program to call another; in this case, JCL can perhaps be used to couple SAMMY's four segments. Alternatively, the four segments could be reunited (thus probably eliminating the SAM20.DAT temporary file) and, to save core, overlaid if possible.

The authors would appreciate feedback concerning the ease or difficulty of implementing SAMMY on other computers. 


\section{APPENDIX C. INPUT TO SAMMY}

A minimum of three user-supplied input files are required to run SAMMY. The first, or "INPut" file, contains general information about the interaction being studied, quantum numbers for nucleus and resonances, and output control information. The second, or "PARameter" file, gives initial estimates for resonance parameters and (perhaps) initial estimates for correlations between parameters. The third, or "DATa" file, provides the experimental energies, data, and uncertainties. An optional fourth, or "CøVariance" file, contains the covariance matrix for the parameters in binary form, as generated by a previous SAMMY run. An optional fifth, or "DCV" (data covariance) file, provides off-diagonal data covariances.

The PAR and DAT files are identical to the analogous files required by program MULTI, except that the PAR file may have information about parameter uncertainties appended to it. The DAT file is not restricted to those data points needed for a particular calculation; SAMMY will search through the file to find only those points within the desired energy range. SAMMY's INP file contains much of the same information as does MULTI's INP file, but formats have been changed and controls are now written in English rather than as numbers in certain columns. These changes were designed to eliminate input errors as much as possible. Details and formats for the INP file are given in Tables $C .1$ and $C .2$, for PAR in Table C.3, for DAT in Table C.4, and for DCV in Table C.5. Note that this format for the PAR file permits a maximum of three neutron + fission channels, though there is no such limitation inherent in SAMMY; modifications of input and output formats to permit more than three channels will be made as they are needed. 
TABLE C.1. FORMAT OF THE INPUT FILE

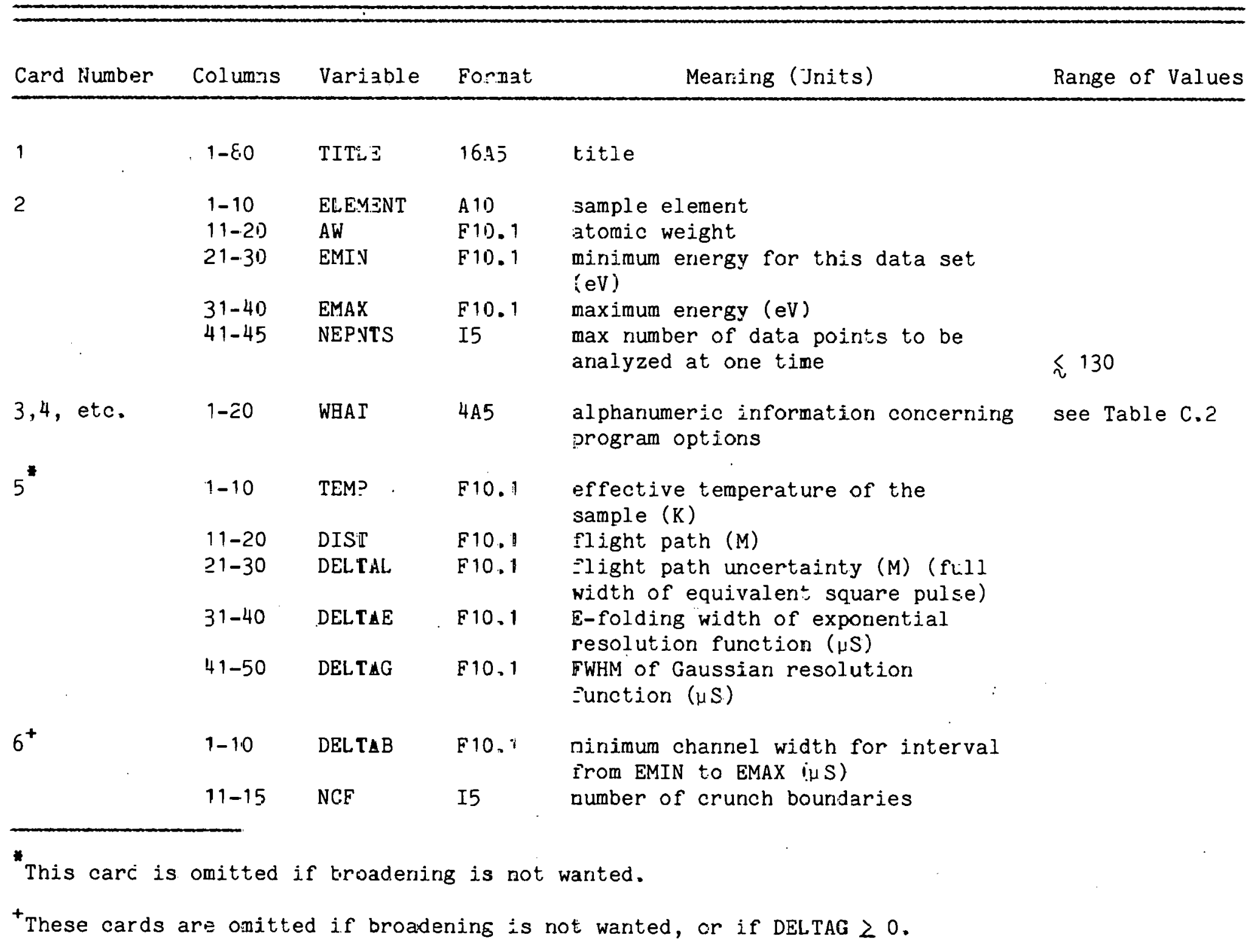


TABLE C. 1. FORMAT OF THE INPUT FILE (CONT'D)

\begin{tabular}{|c|c|c|c|c|c|c|}
\hline Card & Number & Columns & Variable & Format & Meaning (Units) & Range of Values \\
\hline $7^{+}$ & & $\begin{array}{l}1-10 \\
11-20 \\
\text { etc. }\end{array}$ & $\begin{array}{l}(B C F(I) \\
C I(I) \\
I=1, N C F)\end{array}$ & $8 \mathrm{~F} 10.1$ & $\begin{array}{l}\text { crunch boundaries, read in increasing } \\
\text { energy order (eV); crunch factors } \\
\text { (integer units of DELTAB). }\end{array}$ & \\
\hline \multirow[t]{3}{*}{8} & & $1-10$ & CRFN & F 10.1 & $\begin{array}{l}\text { channel radius }(\mathrm{eV}) \text { or, if input as } \\
\text { zero, computed as } 1.45^{*} \\
(1.009+\mathrm{AW}) * 0.333\end{array}$ & 20 \\
\hline & & $\begin{array}{l}11-20 \\
21-30\end{array}$ & $\begin{array}{l}\text { THICK } \\
\text { DCøVA }\end{array}$ & $\begin{array}{l}\text { F10.1 } \\
\text { F10.1 }\end{array}$ & $\begin{array}{l}\text { sample thickness (AT/B) } \\
\text { data covariance matrix has }\end{array}$ & \\
\hline & & $31-40$ & $\mathrm{DC} \oslash \mathrm{VB}$ & F 10.1 & $\begin{array}{l}\text { additional term of the form } \\
\left(D C \emptyset V A+E_{i}^{*} D C \emptyset V B\right) *\left(D C \emptyset V A+E_{j}^{*} D C \emptyset V B\right)\end{array}$ & \\
\hline \multirow[t]{2}{*}{9} & $\cdot \cdot$ & $1-80$ & CRøSS & $16 \mathrm{~A} 5$ & $\begin{array}{l}\text { type of cross-section (only the } \\
\text { first five characters are relevant) }\end{array}$ & $\begin{array}{l}\text { TØTAL } \\
\left\{\begin{array}{l}\text { ELASTic } \\
\text { SCATTering }\end{array}\right. \\
\left\{\begin{array}{l}\text { FISSIon } \\
\text { REACTion }\end{array}\right. \\
\text { CAPTUre }\end{array}$ \\
\hline & $\cdot$ & & .. & & & $\begin{array}{l}\text { NOTE: If TøTAL } \\
\text { cross section, } \\
\text { transmission data } \\
\text { is assumed unless } \\
\text { the letters "CRøSS" } \\
\text { appear in columns } \\
26-30\end{array}$ \\
\hline 10 & & $\begin{array}{l}1-10 \\
11-20\end{array}$ & $\begin{array}{l}\text { SPINI } \\
\text { ECHAN (1) }\end{array}$ & $\begin{array}{l}\text { F10.1 } \\
\text { F10.1 }\end{array}$ & $\begin{array}{l}\text { SPIN of target nucleus } \\
\text { energy of R-matrix channel } 1 \\
\text { relative to neutron binding } \\
\text { energy }(\mathrm{eV})\end{array}$ & half integer \\
\hline
\end{tabular}


TABLE C. 1 . FORMAT OF THE INPUT FILE (CONT'D)

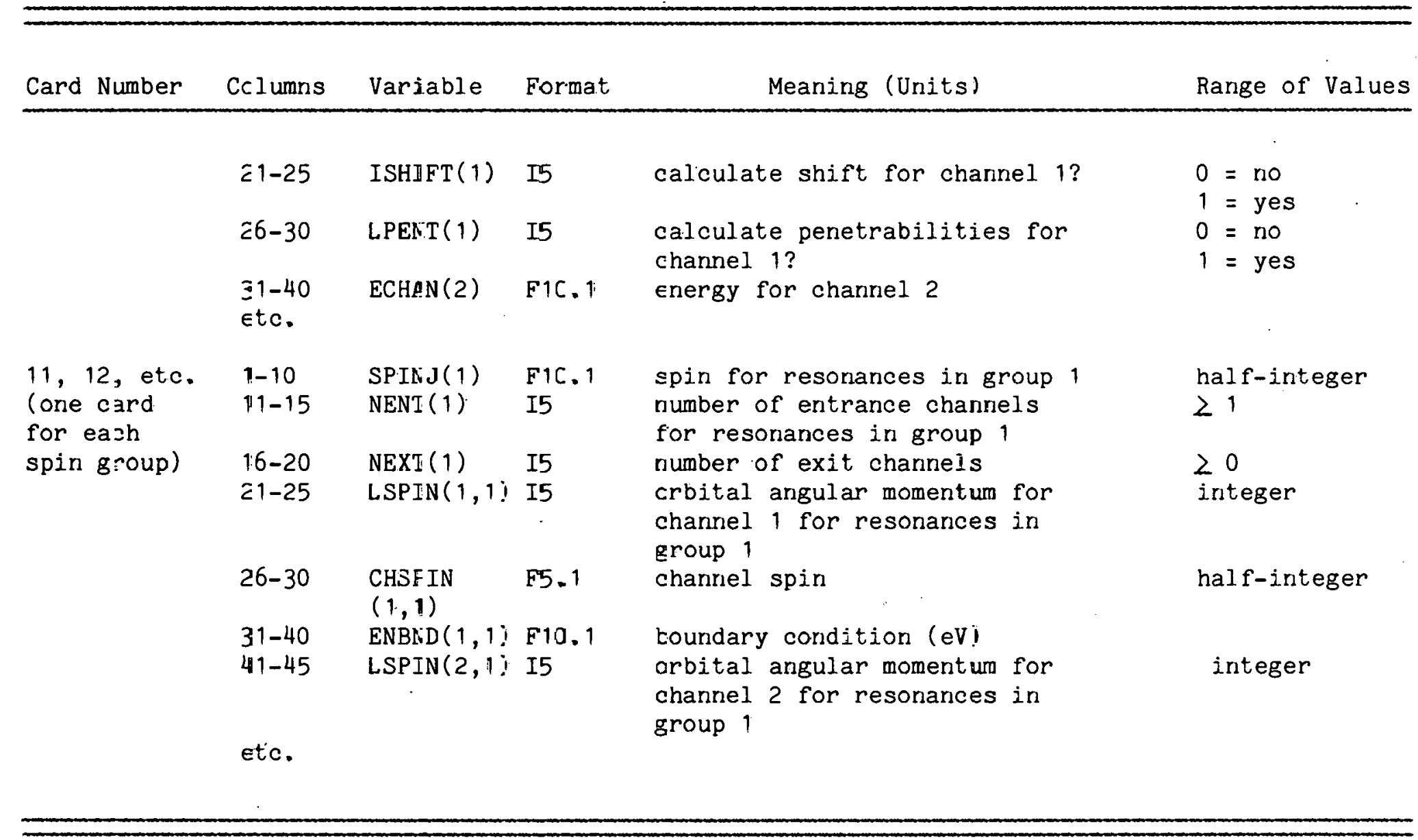


TABLE C.2. ACCEPTABLE "ALPHANUMERIC INFORMATION CONCERNINIG PROGRAM OPTIONS", FOR CARDS 3, 4, ... IN THE INPUT FILE. Any of the listed statements may be used, in any order, terminating with a blank line. Only the first twenty characters and occasional others (capitalized below) need be exactly as shown here. Defaults are indicated in the first column.

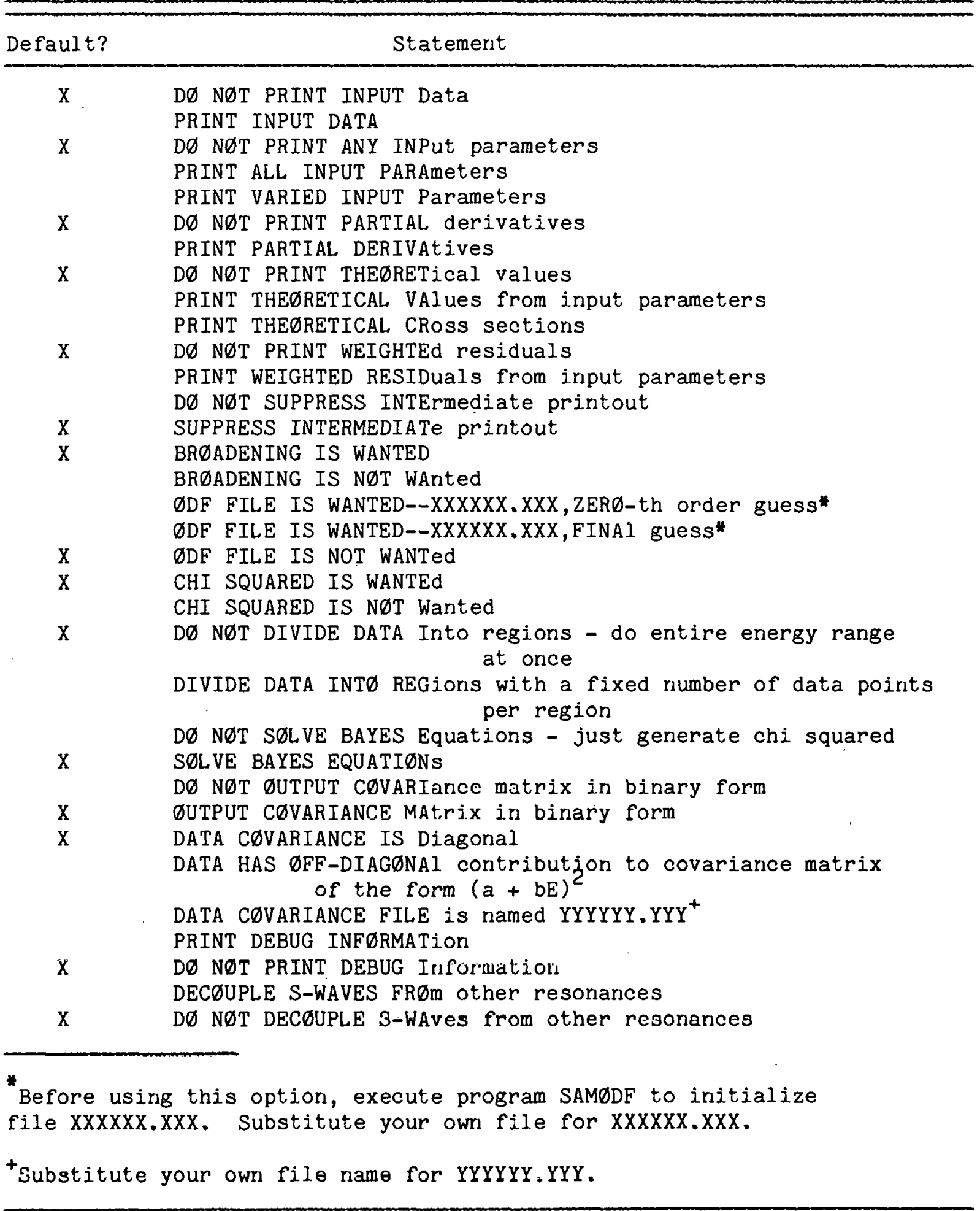


TABLE C. 3. FORMAT OF THE PARAMETER FILE

\begin{tabular}{|c|c|c|c|c|c|}
\hline Card & Col umn & $\begin{array}{c}\text { Variable } \\
\text { Name }\end{array}$ & Format & Meariling (Units) & Values \\
\hline \multirow{11}{*}{$\begin{array}{l}1,2, \\
\text { etc. }\end{array}$} & $1-11$ & ERES & E11.4 & Resonance Energy (eV) & \\
\hline & $12-22$ & $r^{\gamma}$ & E11.4 & Gamma-width (Milli-eV) & \\
\hline & $23-33$ & $\Gamma_{c 1}$ & E 11.4 & width for channel 1 (MJ.Jul-eV) & \\
\hline & $34-44$ & $\Gamma_{c 2}$ & E11.4 & width for channel 2 (MjJji-eV) & \\
\hline & $45-55$ & $\Gamma_{c 3}$ & E11.4 & width for channe 3 (Mj.Jl $1-\mathrm{eV})$ & \\
\hline & $56-57$ & IS $_{\text {ERES }}$ & 12 & vary ERES? & $\begin{array}{l}0=\text { rno } \\
1=\text { yes }\end{array}$ \\
\hline & $58 \cdot 5 ?$ & $\mathrm{IF}$ & I2 & vatiy $r_{Y}^{t}$ & $\begin{array}{l}u=n o \\
1=\text { yes }\end{array}$ \\
\hline & $60-61$ & IS $_{\mathrm{eI}}$ & 12 & vary $r_{c 1} ?$ & $\begin{array}{l}0=\text { no } \\
1=\text { yes }\end{array}$ \\
\hline & 62.63 & $1 s_{\mathrm{c} 2}$ & 12 & vary $r_{c ?} ?$ & $\begin{array}{l}0=\text { no } \\
1=\text { yes }\end{array}$ \\
\hline & $64-65$ & IS $_{\mathrm{c} 3}$ & 12 & $\operatorname{vary} \Gamma_{\mathrm{c} 3} ?$ & $\begin{array}{l}0=\text { nn } \\
1=\text { yes }\end{array}$ \\
\hline & $66-67$ & IGRGUP & I2 & $\begin{array}{l}\text { quantium numbers for this } \\
\text { resonance are those of } \\
\text { groud number IGRGIIP } \\
\text { (See cards } 11,12 \text {, etc. } \\
\text { in Tabje C. } 1 . \text { ) }\end{array}$ & \\
\hline
\end{tabular}


TABLE C.3. FORMAT OF THE PARAMETER FILE (CONT'D)

\begin{tabular}{|c|c|c|c|c|c|}
\hline Card & Co] umrı & $\begin{array}{l}\text { Varjable } \\
\text { Name }\end{array}$ & Format. & Mearitng (Units) & Values \\
\hline & $68-80$ & DCøV & E.13.4 & $\begin{array}{l}\text { constant off-diagonal data } \\
\text { covariance to be used under } \\
\text { this resonance }\end{array}$ & \\
\hline 3 & & & . & & b) ank \\
\hline 4 & $1-11$ & FUDGE & E11.4 & $\begin{array}{l}\text { prior parameter uncertajinty } \\
\text { is FUDGE tjmes parameter value }\end{array}$ & $\begin{array}{l}0 . \text { ( FUDGE. } \\
(0.1 \text { is default })\end{array}$ \\
\hline $\begin{array}{l}5,6, \\
\text { et.c. }\end{array}$ & $\begin{array}{l}1-5 \\
6-10 \\
11-15 \\
16-20 \\
21-30\end{array}$ & $\begin{array}{l}\operatorname{NN}(1) \\
\operatorname{MM}(1) \\
\operatorname{KK}(1) \\
\operatorname{LL}(1) \\
\operatorname{VV}(1)\end{array}$ & $\begin{array}{l}\text { I5 } \\
\text { I5 } \\
\text { I5 } \\
\text { I5 } \\
\text { F }\end{array}$ & 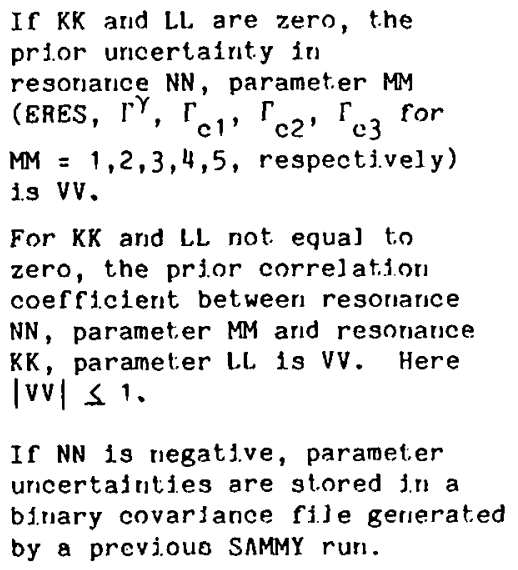 & $\begin{array}{l}\text { NN and KK } \\
S \text { the number } \\
\text { of resonances; } \\
\text { MM and LL } S \\
\text { the number of } \\
\text { channels }+2 \text {. }\end{array}$ \\
\hline
\end{tabular}


TABLE C.4. FORMAT OF THE DATA FILE

Energies are assumed order from high to low, with three data points per line.

\begin{tabular}{|c|c|c|c|c|}
\hline Card & Column & Variable & Format & Meaning (Units) \\
\hline \multirow[t]{9}{*}{1,2, etc. } & $1-15$ & ENERGY & $\mathrm{E} 15.8$ & energy (eV) \\
\hline & $16-30$ & $\mathrm{DATA}_{1}$ & E15.8 & $\begin{array}{l}\text { experimental cross } \\
\text { section (barns) } \\
\text { or transmission }\end{array}$ \\
\hline & $31-17$ & $\mathrm{FRACT}_{1}$ & F7. 5 & $\begin{array}{l}\text { fractional } \\
\text { uncertainty in } \\
\text { DATA }_{1}\end{array}$ \\
\hline & $38-52$ & ENERGY $_{2}$ & $E 15.8$ & \\
\hline & $53-67$ & $\mathrm{DATA}_{2}$ & $E 15.8$ & \\
\hline & $68-74$ & FRACT $_{2}$ & F7. 5 & \\
\hline & $75-89$ & ENERGY $_{3}$ & E15.8 & \\
\hline & $90-104$ & $\mathrm{DATA}_{3}$ & $\mathrm{E} 15.8$ & \\
\hline & $105-111$ & FRACT $_{3}$ & F7. 5 & \\
\hline
\end{tabular}


TABLE C.5. FORMAT OF THE DCV FILE

\begin{tabular}{|c|c|c|c|c|}
\hline Card & Columns & Variable & Format & Meaning \\
\hline 1 & $1-10$ & $\operatorname{VARDAT}(1,1)$ & $\mathrm{F} 10.1$ & Variance for data point 1 \\
\hline \multirow[t]{2}{*}{2} & $1-10$ & $\operatorname{VARDAT}(2,1)$ & F10.1 & $\begin{array}{l}\text { Covariance between data } \\
\text { points } 1 \text { and } 2\end{array}$ \\
\hline & $11-20$ & $\operatorname{VARDAT}(2,2)$ & F10:1 & Variance for data point 2 \\
\hline \multirow[t]{3}{*}{3} & $1-10$ & $\operatorname{VARDAT}(3,1)$ & F 10.1 & $\begin{array}{c}\text { Covariance between data } \\
\text { points } 1 \text { and } 3\end{array}$ \\
\hline & $11-20$ & $\operatorname{VARDAT}(3,2)$ & F 10.1 & $\begin{array}{l}\text { Covariance between data } \\
\text { points } 2 \text { and } 3\end{array}$ \\
\hline & $21-30$ & $\operatorname{VARDAT}(3,3)$ & F 10.1 & Variance for data point 3 \\
\hline 4 & $\begin{array}{l}1-10 \\
\text { etc. }\end{array}$ & $\operatorname{VARDAT}(4,1)$ & F10.1 & $\begin{array}{l}\text { Covariance between data } \\
\text { points } 4 \text { and } 1\end{array}$ \\
\hline \multicolumn{5}{|c|}{$\begin{array}{l}\text { Note that the ordering of data points is low energy to high, and only } \\
\text { those data points to be used in the calculation can be referenced in } \\
\text { the DCV file. A more convenient format for input of off-diagonal data } \\
\text { covariances will be implemented as it is required. }\end{array}$} \\
\hline
\end{tabular}


Execution of SAMMY can proceed interactively, with the user responding to teletype prompts from SAMMY, or in the BATCH mode with responses given as part of the input stream. Teletype prompts and appropriate responses are described in Table C.6.

Output from SAMMY consists of two (or three) files, described in Table C.7.

Conversion of a MULTI-type INP file to a SAMMY-type INP file may be accomplished by running Program SAMSWI; teletype prompts and appropriate responses for SAMSWI are given in Table C.8. The user is urged to compare the SAMMY INP file to Table C.2, to be sure the appropriate options are chosen.

Plotting routines are not an integral part of the code SAMMY. Rather, SAMMY writes theoretical values for cross sections or transmissions on an ØDF (ØRELA data format) file, from which plots may be produced using ØPRØDF (CR78). Because of the sequential nature of data analysis in SAMMY, it is necessary to initialize the UbF' t'ile prior to running SAMMY. 'l'o accomplish this, program SAMØDF generates a five- (or nine-) section ØDF file and inserts energies and experimental data in the appropriate sections. Details are given in Tables $C .9$ and $C .10$. 
TABLE C.6. TELETYPE INPUT FOR SAMMY

1. What is the name of the input file?

2. What is the name of the parameter file?

3. What is the first data file name? EMIN? EMAX?

4. What is the name of the covariance file? (Optional question, asked only if parameter file indicates there is a covariance file.)

5. What is new EMIN? EMAX? Data set name?
Input file rame plus extension, e.g., AAAAAA. INP*

PARameter file rame, e.g., AAAAAA.PAR*

DATa file rame, e.g., AAAAAA.DAT*, followed by the mirimum and maximum energies (in eV) for this step in F format, separated by commas. EMIN and EMAX need not be repeated here if they are correct in the INP file, card 2 . Caution: Be sure EMIN does rot start prior to Column (or Space) 11.

Binary file from a previous SAMMY run, e.g., AAAAAA.C $\varnothing V^{*}$
Energy range (in eV) for the next step, in $F$ format, separated by commas. If EMIN $=0 .$, program will terminate. If the data set rame is blank, the previous DATa file is assumed.

Repeat Steen 5 as rueeded

*File names may be choser for converience; exterisions need not be INP, $P A R, D A T$, and $C ø V$. 
TABLE C.7. SAMMY OUTPUT FILES

File Name Contents

SAMMY.LPT

Descriptive output, to be queued to the line printer for examination.

SAMMY.PAR

New resonance parameters, in the same format as the input PARameter file. For binary output of the covarlance matr1x, "-1" w1ll occur in columns 4 and 5 on the last card of SAMMY.PAR.

SAMMY.COV

New covariance matrix for the parameters, in binary (opt.innal) form. 
TABLE C.8. TELETYPE INPUT FOR SAMSWI

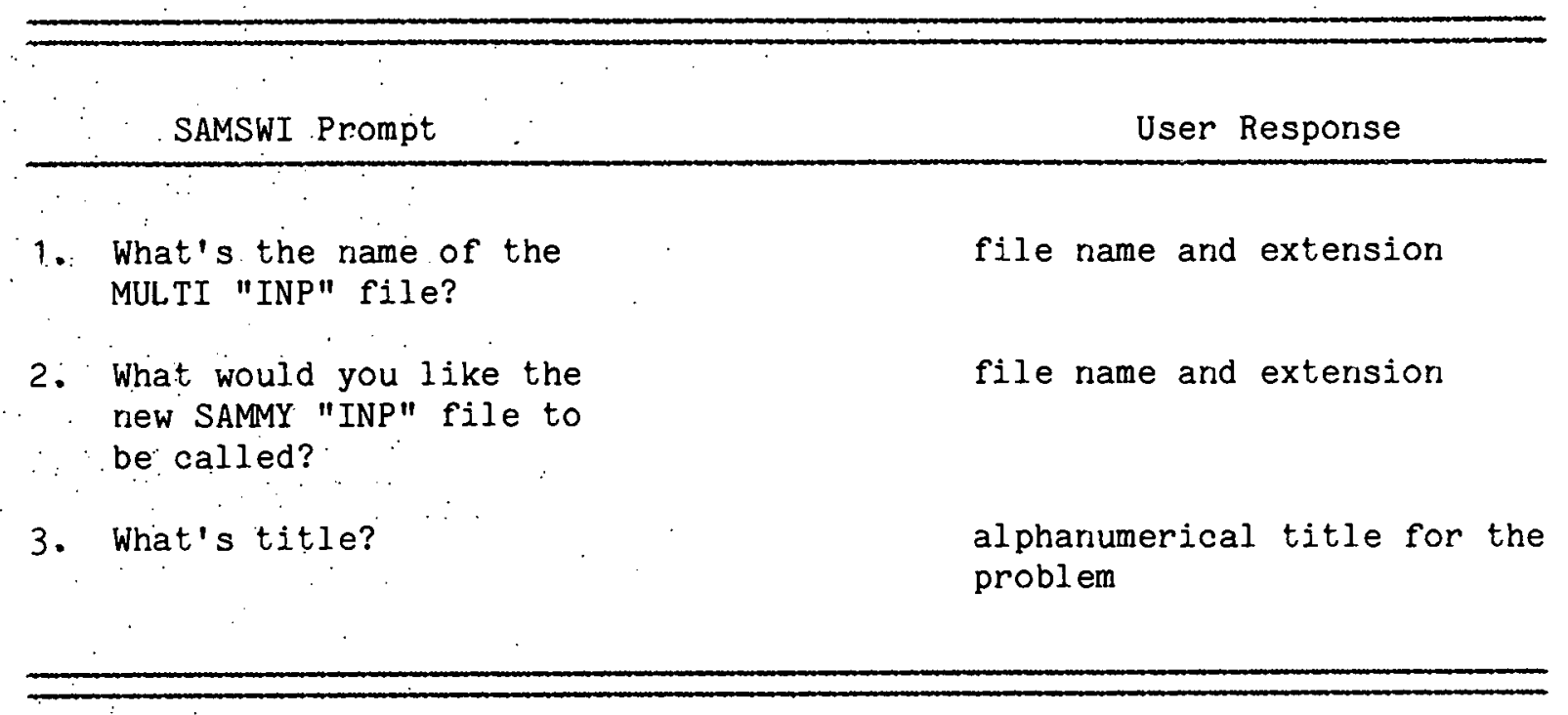


TABLE C.9. TELETYPE INPUT FOR SAMøDF

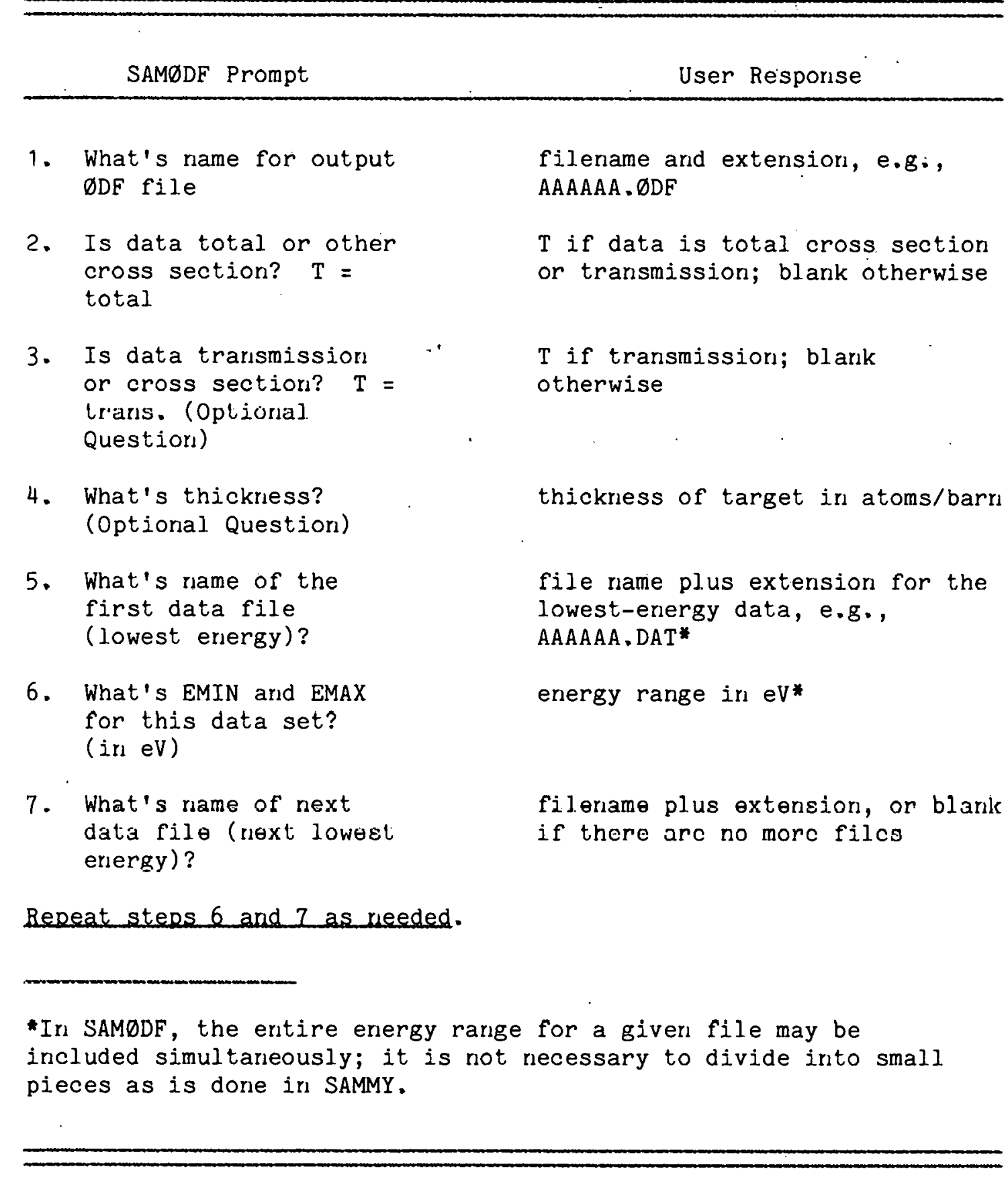


TABLE C. 10. SECTIONS OF ØDF FILE GENERATED BY SAMøDF

\begin{tabular}{ll} 
Section Number & \multicolumn{1}{c}{ Contents } \\
\hline 1 & energy (keV) \\
& experimental cross section (barrs) \\
3 & $\begin{array}{l}\text { uncertainty in experimental cross section } \\
\text { (barns) }\end{array}$ \\
4 & $\begin{array}{l}\text { zeroth order theoretical cross section as } \\
\text { evaluated by SAMMY } \\
\text { final theoretical cross section as evaluated } \\
\text { by SAMMY } \\
6^{*}\end{array}$ \\
$7^{*}$ & $\begin{array}{l}\text { experimental transmission } \\
\text { (absolute) }\end{array}$ \\
& $\begin{array}{l}\text { zeroth order theoretical transmission as } \\
\text { evaluated by SAMMY }\end{array}$ \\
& $\begin{array}{l}\text { final theoretical transmission as evaluated } \\
\text { by SAMMY }\end{array}$
\end{tabular}

* These sections are omitted for the partial cross sections, included for total cross sections or transmissions. 


\section{THIS PAGE}

\section{WAS INTENTIONALLY \\ LEFT BLANK}


APPENDIX D. SAMPLE INPUT AND OUTPUT

Input and output for example number 3 in Section VI are presented in the microfiche inside the back cover of this report. SAMTRY.BAT is the file which should be submitted to the PDP-10 to run SAMMY in the batch mode; equivalently, one could run SAMMY in the interactive mode (via the R SAMMY command) and respond to SAMMY's questions with the answers given in that file.

The file SAMTRY.INP is the INPut file for this example, SAMTRY.PAR the PARameter file, and SAMTRY.DAT the DATa file. The two output files are SAMMY.PAR and SAMMY.LPT. 


\section{THIS PAGE}

\section{WAS INTENTIONALLY LEFT BLANK}


APPENDIX E. FØRTRAN LISTINGS

FØRTRAN listings of all the SAMMY programs are shown on the microfiche inside the back cover of this report. File SAMPAR.F4 contains the listing of the program SAMMY-PARAMETER, SAMDAT.F4 contains SAMMY-DATA, SAMTHE.F4 contains SAMMY-THEØRY, and SAMRES.F4 contains SAMMY-RESULTS. The LINPACK subroutines required by SAMMY-RESULTS are listed in file LINPACK.F4. Program SAMøDF is in file SAMØDF.F4, and SAMSWITCH in SAMSWI F 4 . 
THIS PAGE

\section{WAS INTENTIONALLY LEFT BLANK}


ORNL/TM-7485

ENDF-297

Dist. Category: UC-79d

INTERNAL DISTRIBUTION

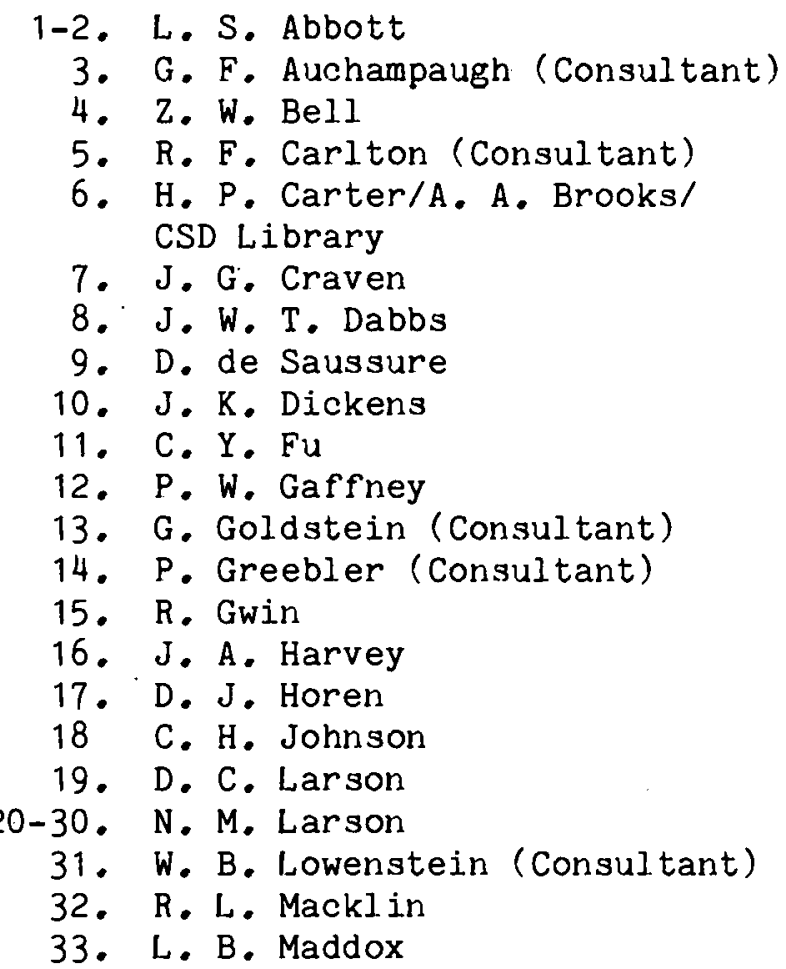

34. F. C. Maienschein

35. B. F. Maskewitz

36. G. S. McNeilly

37. F. W. Nehring

38. D. K. Olsen

39. R. W. Peelle

40. C. M. Perey

41-51. F. G. Perey

52. R. B. Perez

53. R. 0. Sayer

54. R. R. Spencer

55. P. H. Stelson

56. R. E. Uhrig (Consul.tant)

57. L. W. Weston

58. R. Wilson (Consultant)

59. R. Winters (Consultant)

60. Central Research Library

61. ORNL Y-12 Technical Library Document Reference Section

62-63. Laboratory Records Department

64. ORNL Patent office

65. Laboratory Records (RC)

\section{EXTERNAL DISTRIBUTION}

66. Chief, Mathematics and Geoscience Branch, DOE, Washington, DC 20545.

67. DOE Oak Ridge Operations, Reactor Division, P. O. Box E, Oak Ridge, TN 37830: Director.

68. DOE Division of Reactor Research and Development, Washington, DC 20545: Director.

69. J. N. Rogers, Division 8324, Sandia Laboratories, Livermore, CA 94550.

70. Office of Assistant Manager for Energy Research and Development, Department of Energy, Oak Ridge Operations, Oak Ridge, TN 37830

71-303. For distribution as shown in TID-4500 Distribution Category UC-79d, Liquid Metal Fast Breeder Reactor Physics - Base (60 copies - ENDF distribution). 